\title{
Las fuentes del estilo: distribución regional de canteras y técnicas alfareras en Conchucos (Ancash, Perú)
}

Les sources du style: distribution régionale et techniques potières à Conchucos (Ancash, Pérou)

The sources of style: distribution of quarries and pottery techniques in Conchucos (Ancash, Peru)

\section{Gabriel Ramón}

\section{OpenEdition}

Journals

Edición electrónica

URL: http://journals.openedition.org/bifea/1061

DOI: 10.4000/bifea.1061

ISSN: 2076-5827

Editor

Institut Français d'Études Andines

Edición impresa

Fecha de publicación: 1 abril 2013

Paginación: 29-90

ISSN: 0303-7495

Referencia electrónica

Gabriel Ramón, «Las fuentes del estilo: distribución regional de canteras y técnicas alfareras en Conchucos (Ancash, Perú) », Bulletin de l'Institut français d'études andines [En línea], 42 (1) | 2013 ,

Publicado el 01 agosto 2013, consultado el 05 noviembre 2020. URL : http://journals.openedition.org/ bifea/1061 ; DOI : https://doi.org/10.4000/bifea.1061

\section{cc) (†) $\odot$}

Les contenus du Bulletin de l'Institut français d'études andines sont mis à disposition selon les termes de la licence Creative Commons Attribution - Pas d'Utilisation Commerciale - Pas de Modification 4.0 International. 


\title{
Las fuentes del estilo: distribución regional de canteras y técnicas alfareras en Conchucos (Ancash, Perú)
}

\author{
Gabriel Ramón*
}

\begin{abstract}
Resumen
Para afinar su reconstrucción de las sociedades precoloniales andinas, en las últimas décadas los arqueólogos han incrementado su interés por las relaciones entre canteras de materias primas y productos finales (vasijas). Sin embargo, todavía carecen de modelos sistemáticos para explicar tales vínculos. Del mismo modo, el concepto de estilo técnico está adquiriendo mayor importancia para aproximarse a las identidades colectivas en el pasado remoto. Enseguida haremos una exploración coordinada de ambos temas para la región de Conchucos (Ancash) definiendo tres estilos técnicos, y mostrando sus relaciones con la distribución geográfica de las canteras de materias primas. Finalmente, analizaremos los potenciales corolarios de esta asociación para la arqueología precolonial.
\end{abstract}

Palabras claves: estilos técnicos, canteras de materias primas, Conchucos, producción alfarera, etnoarqueología

\section{Les sources du style : distribution régionale et techniques potières à Conchucos (Ancash, Pérou)}

\section{Résumé}

Pour permettre une reconstruction plus fine des sociétés précoloniales andines, les archéologues ont montré au cours des dernières décennies, un intérêt croissant pour les relations entre sources de matières premières et produits finis (poterie). Cependant, nous manquons encore de modèles systématiques pour expliquer ces liens. De même, la notion de style technique est devenue plus importante pour comprendre les identités collectives dans le passé lointain. Nous procèderons ensuite à un examen coordonné de ces deux questions pour la région de Conchucos (Ancash), et nous définirons trois styles techniques, pour montrer leurs relations avec la distribution géographique des

* Profesor ordinario, Departamento de Humanidades, Pontificia Universidad Católica del Perú. Av. Universitaria 1801, Lima 31. E-mail: glramon@pucp.edu.pe 
sources de matières premières. Enfin, nous analyserons les corollaires de l'association entre les styles techniques et les matières premières pour l'archéologie précoloniale.

Mots clés : styles techniques, source de matières premiers, Conchucos, production de poterie, ethnoarchéologie

\title{
The sources of style: distribution of quarries and pottery techniques in Conchucos (Ancash, Peru)
}

\begin{abstract}
In order to refine their explanation of pre-colonial societies in the Andes, archaeologists have paid increasing interest to the relations between sources of raw materials and final products (pots). However, they lack systematic models to explain those links. In parallel, the concept of technical style is becoming more important for understanding collective identities in the remote past. In this article, coordinated exploration of both topics is made in the Conchucos region (Ancash): three technical styles are defined and their relations with the geographical distribution of raw material sources are shown. Finally, the potential corollaries of the link made between technical styles and raw materials for pre-colonial archaeology are analyzed.
\end{abstract}

Keywords: technical styles, sources of raw materials, Conchucos, pottery production, ethnoarchaeology

Sobre todo, óyelo bien, no has viajado a Huari por ollas, a Huacho por sal,

a Sayán por ají (....). No entiendes todavía el quipu, no sabes catipar, ni distinguir los jircas buenos de los malos, ni sus enemigos.

Enrique López-Albújar (1937:14) [Chupán, Huánuco] ${ }^{1}$

\section{INTRODUCCIÓN}

Desde sus inicios la arqueología andina se ha apoyado en una serie de premisas sobre la relación entre conjuntos de vasijas cerámicas y grupos sociales (Uhle, 1902). Una de ellas sostiene que el área de distribución de objetos con un mismo estilo decorativo estaría marcando un territorio caracterizado por alguna forma de identidad colectiva, denominada cultura o etnia, según las cambiantes nomenclaturas. Hace varias décadas, algunos arqueólogos comenzaron a cuestionar esta premisa para los contextos precoloniales andinos. Mientras trabajaban en dos partes distantes y distintas de los Andes peruanos, Rowe (1944: 43) y Morales (1981: 45-6) observaron que las áreas de distribución de vasijas no

1 El escritor López-Albújar fue juez de primera instancia en Huánuco (1917-1923), y escribió un valioso ensayo etnográfico sobre la lógica del sistema legal de Chupán (López-Albújar, 1939). 
necesariamente coincidían con los límites geográficos de las unidades sociales que las produjeron. Aunque estas valiosas advertencias pasaron desapercibidas entre arqueólogos andinistas, más recientemente se han ido documentando sistemáticamente situaciones análogas en diversas partes del mundo (Dietler \& Herbich, 1994, para Kenia; Petrequin \& Petrequin, 1999, para Nueva Guinea, inter alia). Esta constatación etnográfica generalizada ha dejado en evidencia la necesidad de emplear más puntos de referencia para definir arqueológicamente las identidades colectivas, reforzando el interés por los lugares y las técnicas de producción alfarera (p.e. Tschauner, 2006, para el Intermedio Tardío en Pampa de los Burros, Lambayeque). Al complementar las áreas de distribución con las áreas de manufactura, se está pasando también del estilo decorativo al estilo técnico.

Analizar objetos cerámicos desde la perspectiva del estilo técnico permite asumir el valor estilístico del conjunto de pasos de la cadena operativa (Gosselain, 2002: 10). De ese modo, tales etapas (desde la recolección de las materias primas hasta la decoración posmanufactura) no son consideradas como procedimientos universalmente preestablecidos, antes bien vinculados a los saberes locales: potencialmente variables y culturalmente informativos ${ }^{2}$. Esta aproximación al material cerámico resulta más exhaustiva que la tradicional, usualmente centrada en lo decorativo ya que requiere localizar (práctica o teóricamente) cada uno de los pasos del ciclo vital de los productos alfareros (ide dónde provienen sus materias primas?, ¿dónde fue elaborada la vasija?, ¿dónde fue usada?, etc.). Por ello, además de contrastar mapas de áreas de distribución y áreas de manufactura los arqueólogos están explorando las relaciones entre productos finales y canteras de materias primas. Las investigaciones en este último rubro están en ciernes en los Andes centrales, por lo que deseo mostrar la utilidad práctica de incorporar el estilo técnico al estudiar los vínculos entre canteras, vasijas y unidades de identidad colectiva. En esa perspectiva, discutiré enseguida la relación entre la distribución de los estilos técnicos y la localización de canteras en la región de Conchucos, departamento de Ancash. Junto con la presentación sintética de los estilos de manufactura actualmente empleados en esa región, propondré una hipótesis general: la esfera de interacción creada por la circulación y el uso de las materias primas alfareras está íntimamente ligada a la distribución geográfica del estilo técnico.

La comparación regional entre los modos de producir vasijas y la localización de las canteras aquí propuesta para Conchucos no ha sido practicada en otras áreas andinas. En los estudios etnográficos, las discusiones sobre estilo en los Andes suelen centrarse en los estilos decorativos de pueblos específicos (e.g. Arnold, 1993, sobre Quinua, Ayacucho). Sin embargo, siguiendo a Mohr (1984-1985)

2 Si nos restringimos a la manufactura, desde una perspectiva arqueológica, el estilo técnico podría considerarse la impronta de la técnica de manufactura en el objeto. La definición tradicional de estilo en arqueología andina se ha limitado al estilo decorativo, vale decir la decoración y ciertos rasgos de la morfometría. Ya en su estudio sobre los chami (Colombia), Reichel-Dolmatoff (1945: 430) había percibido que el ritmo de cambio del estilo de manufactura era más lento que el de su contraparte decorativa, invitando a los arqueólogos a su estudio. 
conviene ir más allá y observar cómo funciona el estilo técnico en un contexto supra-comunal. Elegimos Conchucos, ya que es la región con mayor densidad de pueblos con alfareros activos en los Andes septentrionales peruanos (Ancash, La Libertad, Lambayeque, Piura, Tumbes). Enseguida mostraré que cuando los poblados con alfareros comparten uno o más yacimientos de materias primas también tienen un mismo estilo técnico precisamente por causa de la constante interacción humana. Si bien el nexo entre yacimientos de arcilla y vasijas ha sido muy explorado desde el punto de vista físico-químico, en esta ocasión incorporo al debate un vínculo social que deja huellas macroscópicas. En la medida que se generalicen estudios semejantes, nuestro modelo podrá ser contrastado con contextos etnográficos, coloniales y precoloniales.

\section{DE LAS CANTERAS A LAS OLLAS}

Al explorar la relación entre canteras y vasijas, arqueólogos y etnógrafos han seguido la misma ruta, pero en direcciones diametralmente opuestas. Los arqueólogos comienzan excavando el producto final (vasijas en contexto) y, luego van en busca de las potenciales canteras, tratando de confirmar el vínculo. Mientras tanto, los etnógrafos pueden observar a los artesanos recolectando sus materias primas y elaborando ollas, para luego describir las relaciones espaciales y culturales entre ambas etapas. Como sabemos, el objetivo en Arqueología no es quedarse en las conexiones físico-químicas entre fuentes geológicas y productos finales sino abordar sus connotaciones sociales. Por ello, las explicaciones arqueológicas — tarde o temprano - acaban hundiendo sus raíces en terreno etnográfico (Arnold et al., 1991: 87-88). Un breve ejemplo precolonial aclarará las expectativas de nuestra exploración en Conchucos.

La literatura andina sobre nuestro tema ha sido principalmente desarrollada alrededor del caso Nasca, un estilo y una cultura del periodo Intermedio Temprano de la costa sur peruana. Los múltiples estudios dedicados a esta atractiva cerámica polícroma han seguido escalonadamente el ciclo de vida de las vasijas (Silverman \& Proulx, 2002: 1-13). Primero, se estableció una secuencia estilística detallada (a) que permitió una refinada discusión cronológica y espacial (Rowe, 1956: 146147, 1960; Roark, 1965; Proulx, 1968: 92-100). Segundo, algunas técnicas de manufactura (b) fueron parcialmente documentadas (Carmichael, 1990; 1998; Gottsmann \& Tellenbach, 2002; y los comentarios de Arnold, 1998: 358). Tercero, las canteras de arcilla (c) han sido parcialmente incorporadas a la discusión (Vaughn \& Neff, 2000; 2004; Vaughn et al., 2006; Vaughn, 2009)33. Simultáneamente, con el desarrollo de estos tres niveles analíticos (a, b, c) las alusiones a los escasos alfareros

3 Enfatizo parcialmente ya que los arqueólogos andinistas no suelen distinguir entre canteras geológicas y canteras culturales (efectivamente usadas). Ni tampoco entre arcilla para adobes, arcilla para vasijas empleadas para preparar comida (sometidas al fuego) y vasijas para servir o almacenar alimentos (no sometidas al fuego). Estas variables son cruciales para entender la relación entre vasijas y canteras. 
locales de Ica han ido aumentando. Sin embargo, las relaciones entre estas etapas (a-b-c) continúan inexploradas tanto arqueológica como etnográficamente. La información recopilada entre los alfareros conchucanos durante la última década nos permitirá explicar las relaciones entre canteras y técnicas (c-b)4.

En la situación ideal que, como arqueólogos, estableciéramos el vínculo físicoquímico entre determinada(s) cantera(s) y un corpus cerámico precolonial específico, ¿qué significaría esto? Podemos comenzar considerando las opciones incluidas en el cuadro 1.

\section{Cuadro 1. Algunas posibilidades de intercambio de materias primas}

Basadas en la información recogida en los Andes septentrionales peruanos (Ramón, 2008a). Nuestra perspectiva es desde la comunidad a.
1. Cantera local
2. Cantera externa y local [simple]
3. Cantera externa [simple]
4. Cantera externa y local [complejo]
5. Cantera externa [complejo]

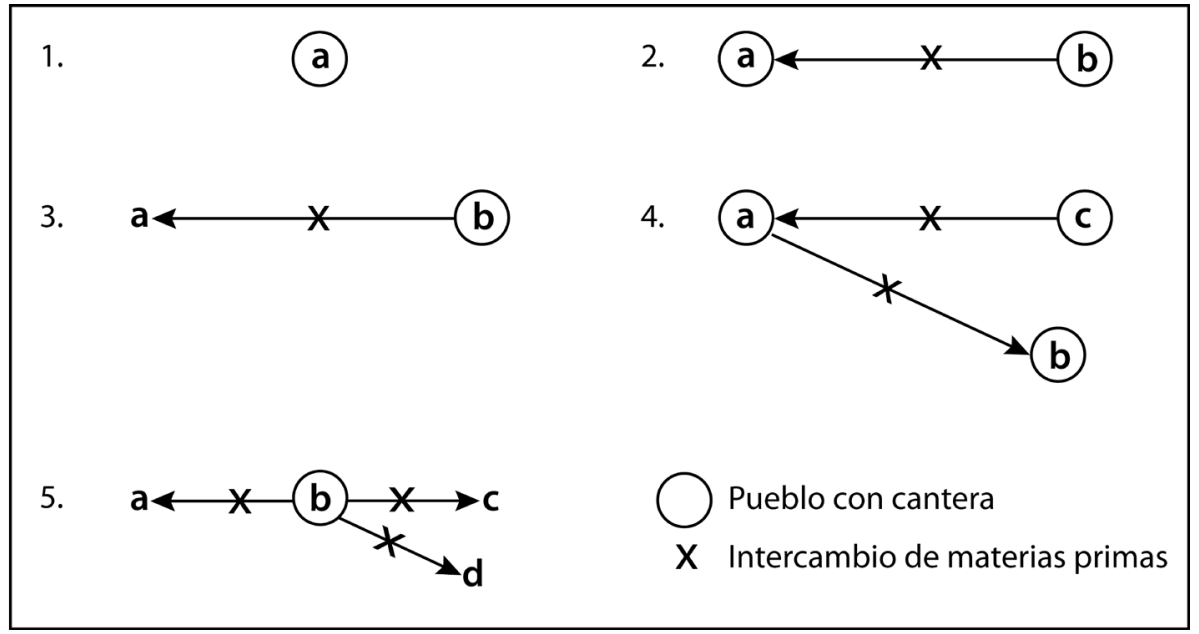

Estas posibilidades son empíricas — las hemos observado en los Andes- y forman parte de una gama mayor de modos de acceder a las materias primas (cf. Renfrew, 1975). Estas posibilidades permiten mostrar que el vínculo físicoquímico no implica resultados sociales automáticos, y nos advierte que así como sucede con las vasijas acabadas, las materias primas también circulan

4 Luego de Nasca tenemos el caso moche (costa norte, Intermedio Temprano) con la misma secuencia de estudios, pero poca exploración de las fuentes (e.g. Chapdelaine et al., 1995; Rohfritsch, 2010). Para otras investigaciones similares en los Andes ver Druc (1998: 16-8) y los primeros pasos del proyecto Pueblo Viejo en Lurín (Lima) (Makowski et al., 2008). En la arqueología mesoamericana estos tres niveles $(\mathrm{a}, \mathrm{b}, \mathrm{c})$ ya han sido ampliamente tratados, y el impacto de los estudios de composición (c) en la interpretación de conjunto puede percibirse en la discusión sobre las vasijas olmeca y el sitio de San Lorenzo (Oaxaca, México) (ver el debate en Latin American Antiquity, 17 (1), 2006). 
entre comunidades. Por ello, es necesario estudiar regiones donde este tipo de fenómeno ha estado presente: así podremos tener una mirada más informada y realista para explicar los contextos arqueológicos ${ }^{5}$. Como bien indicara Arnold (1985: 35) en Arqueología hemos carecido de modelos contextualizados sobre las fuentes de materias primas ya que los reportes etnográficos privilegian desde el momento de la manufactura en adelante (pero ver Gosselain \& Livingstone Smith, 2005). En tal sentido, Conchucos es una región ideal para explorar esta parte inicial del ciclo vital de las ollas de barro ya que las materias primas han estado moviéndose entre sus pueblos con alfareros. Tras definir nuestro escenario, presentamos la información sobre los alfareros y sus técnicas. Luego abordamos la etapa de obtención de materias primas en dos zonas de esa región, enfatizando su relación con el estilo técnico. Concluimos discutiendo las implicancias regionales de este vínculo6.

\section{INGRESANDO A CONCHUCOS}

Actualmente la región de Conchucos tiene siete provincias (Huari, Raimondi, Asunción, Fitzcarrald, Luzuriaga, Pomabamba, Sihuas), que forman la sección nororiental del departamento de Ancash7. De norte a sur, Conchucos comprende al menos 160 km, entre la Cordillera Blanca al oeste, y la cuenca del Marañón al este. Esta región cuenta con un amplio rango de niveles ecológicos habitados: sus secciones más elevadas (jallga o puna, y quechua alta) se ubican al pie de la Cordillera Blanca, las zonas bajas y cálidas están hacia el río Marañón (fig. 1). Hemos identificado cuatro estilos técnicos en Ancash [13-26] tres de ellos en Conchucos (cuadros 2 y 3)8. Basándonos en la ubicación de los lugares de producción con diferentes estilos técnicos, dividimos la región en meridional

5 Ver un ejemplo reciente sobre las hipotéticas relaciones entre yacimientos arcillosos y artesanos en Feltham (2009: 67-8) para Sisicaya precolonial, en la parte media del valle de Lurín, Lima. Como se puede observar en ese ensayo, la interpretación del conjunto depende de esa relación, y algo similar puede verse en la sección sobre cerámica y la interpretación final de Vaughn (2009) sobre Nasca.

6 Mi trabajo de campo en Huaylas (Ancash) comenzó en 1999, pasando a Conchucos en 2000. Posteriormente volví a Huaylas en 2001, y residí como profesor en Conchucos entre abril y julio de 2003, muy cerca de la mayor cantera regional de arcilla, visitándola frecuentemente y entrevistando a alfareros. En 2004 y 2005 realizamos campañas intensivas con un equipo de colegas en diversos pueblos con alfareros conchucanos, desde su extremo sur hasta la frontera con La Libertad. Posteriormente hemos vuelto para realizar algunas entrevistas puntuales (2010, 2011). Además de los diez pueblos con alfareros visitados en esa región se incluye información de Llama (cerca a Piscobamba), registrado por Tello (1920). Nuestra metodología de campo se puede ver en Ramón (2008a: XII-XV).

7 Al comenzar el siglo XX, Conchucos se dividía en dos provincias (Pomabamba y Huari). Definimos Conchucos siguiendo a Chocano (2003) y los mapas de Varallanos (1959: X, XI, XII).

8 En adelante, los números entre corchetes se refieren a los cuadros 2 y 3, con los detalles básicos de los pueblos de alfareros, e.g. [19] es Allpabamba. Para identificar los lugares en relación a las provincias actuales de Conchucos, se añade la primera letra, e.g. Llamellín $[H]$, para Huari. Las distancias son a pie; cuando se indican kilómetros, es en línea recta en el mapa. 


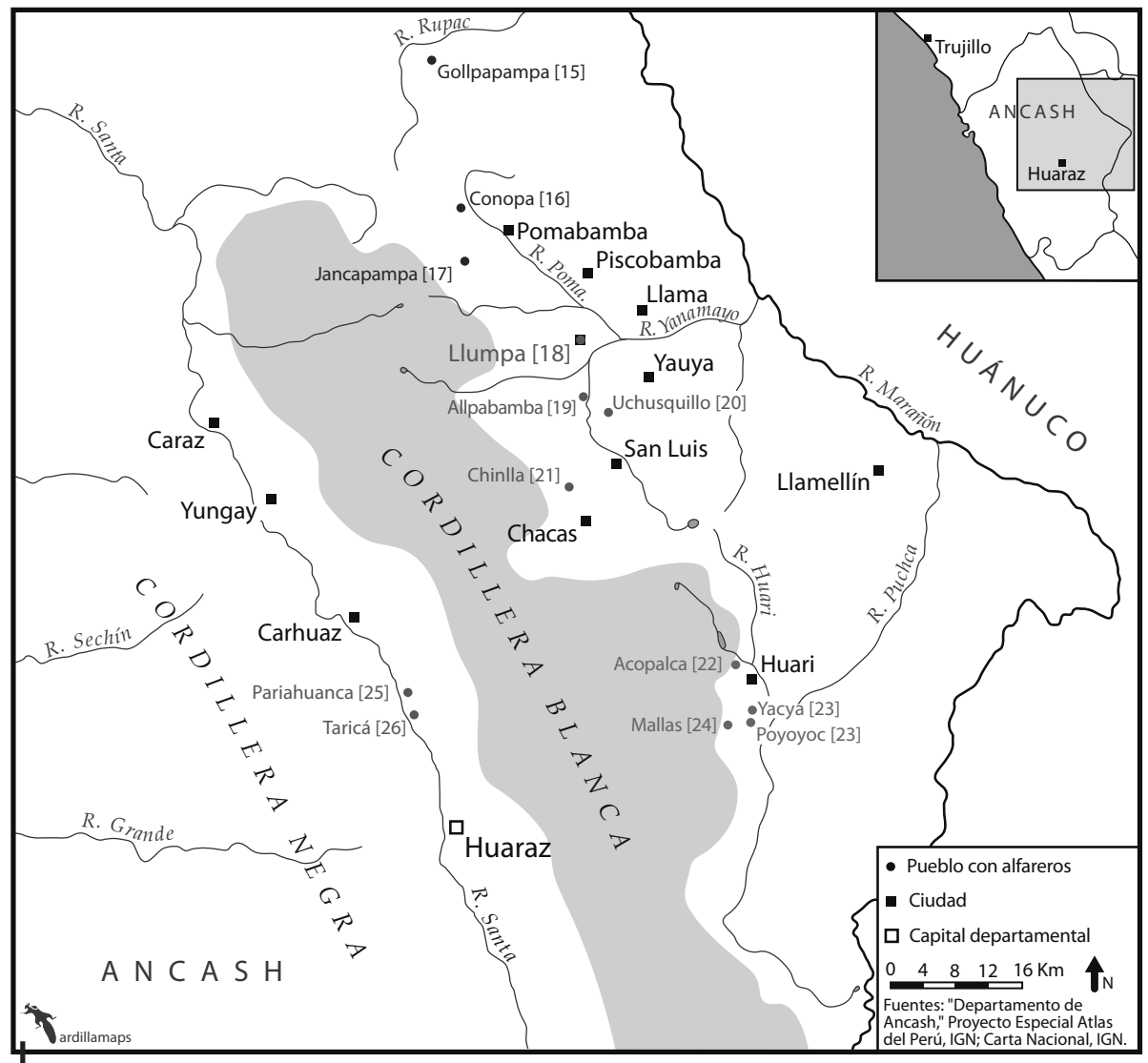

Figura 1 - Pueblos con alfareros en Conchucos

División según estilos técnicos: Septentrional [15, 16, 17], Central [18, 19, 20, 21], Meridional [22, 23, 24]. Dos casos son de Huaylas [25, 26]

$[H, R]$, central $[A, F, L]$ y septentrional $[P, S]$. En esta ocasión enfatizaremos en los dos primeros estilos, con algunas observaciones sobre el tercero9.

La mayoría de los alfareros entrevistados en Conchucos aprendió quechua en casa, y castellano principalmente en la escuela. El quechua ancashino es altamente variable (Parker, 1976: 24-5; Parker \& Chávez, 1976; cf. Middendorf 1974 [1886], III: 25). En nuestras conversaciones con los artesanos conchucanos observamos la variación consistente y paulatina en los términos sobre alfarería en esa región a medida que avanzábamos al norte. Ya que la distribución de los diferentes estilos técnicos muestra una significativa relación con estos cambios en el vocabulario, los iremos señalando ${ }^{10}$.

9 El caso de Conchucos septentrional será objeto de una futura publicación.

10 Para las diferencias entre quechua del norte y sur de Conchucos, ver algunos ejemplos en ethnologe. com. Al nombrar materiales y objetos mantendremos la pronunciación local, para mostrar la variedad. 
Gabriel Ramón

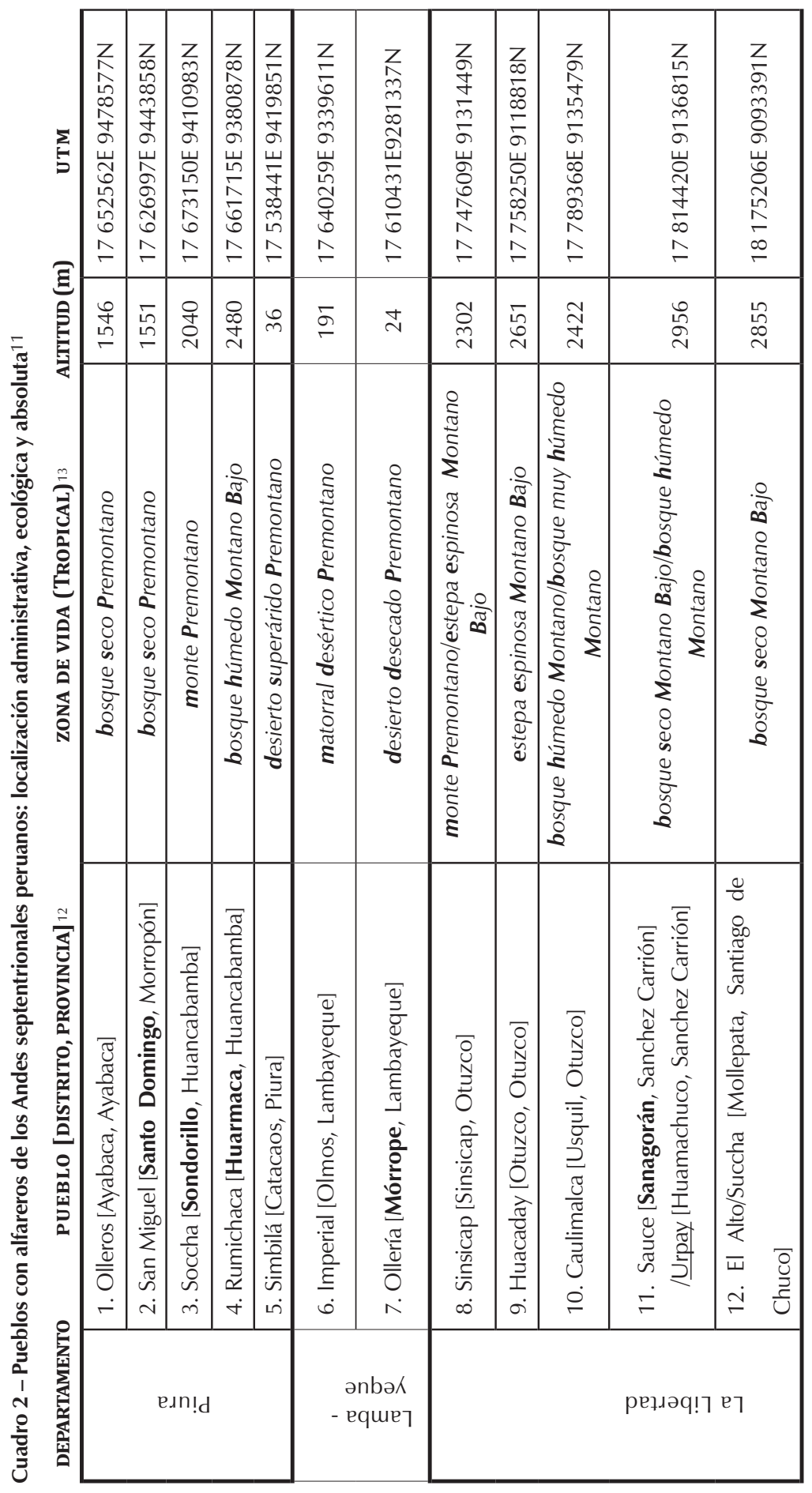


Distribución regional de canteras y técnicas alfareras en Conchucos (Ancash, Perú)

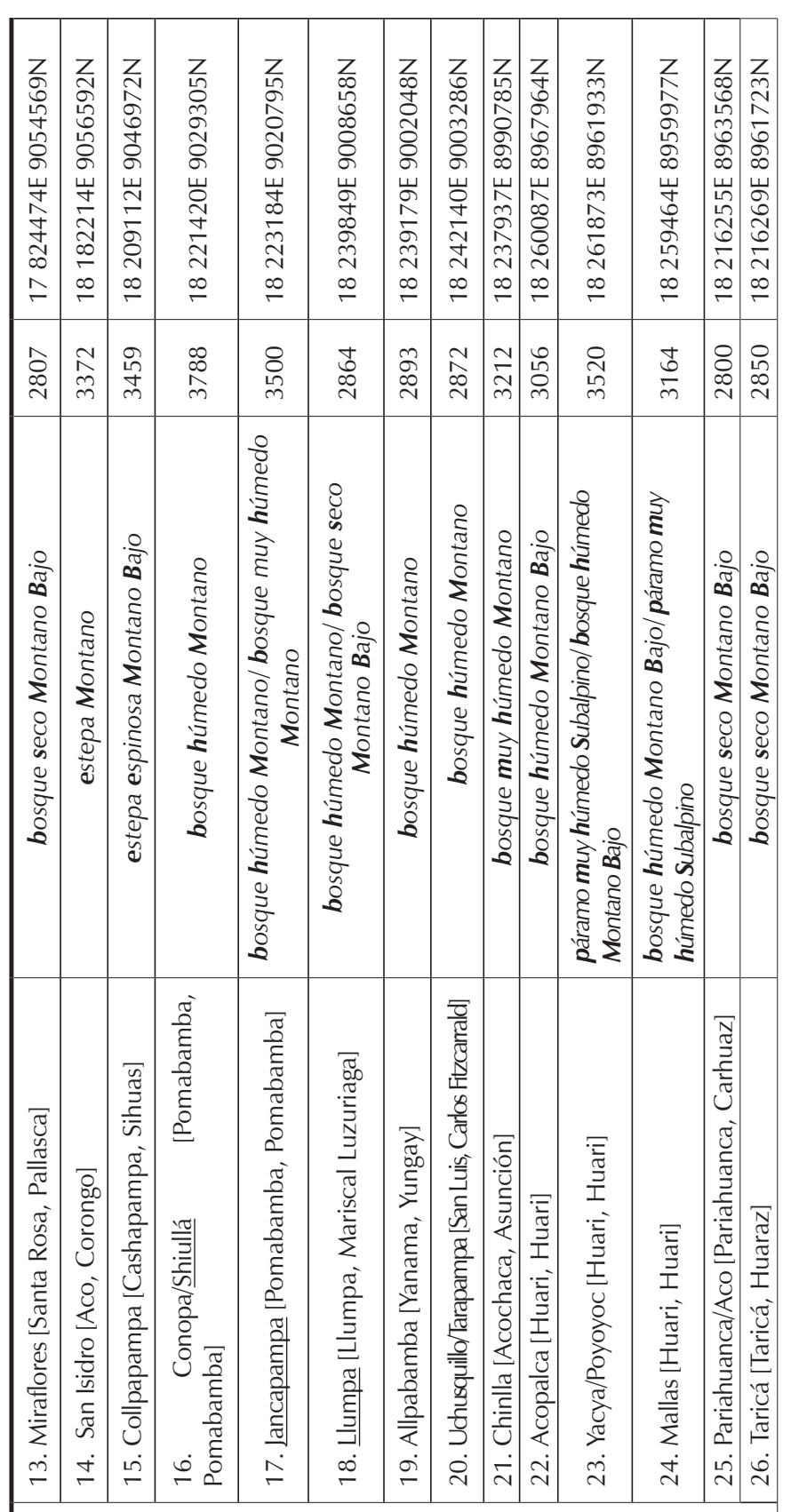

ysejue

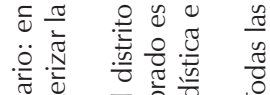

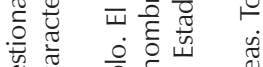

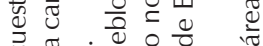

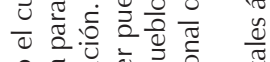

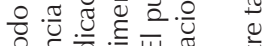

㐫.

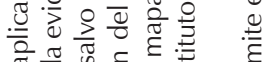

ฮั

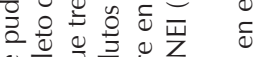

$\&$ 은

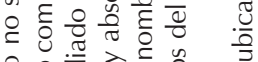

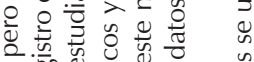

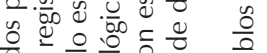

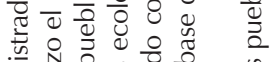

.h.

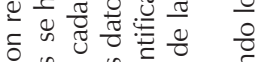

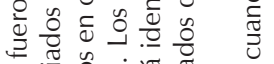

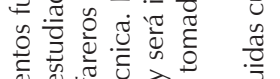

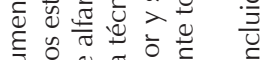

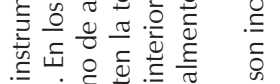

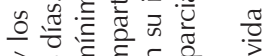
बे

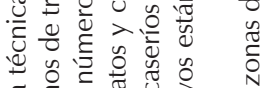

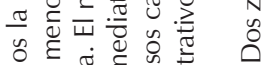
है वं है

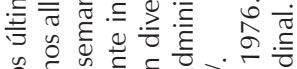
น ह

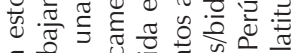
ज羟记

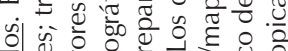

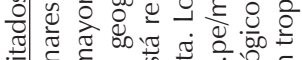
.

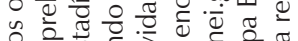
웡

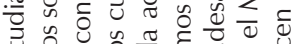

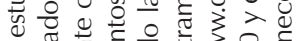
듄

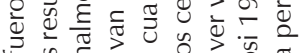
을 है

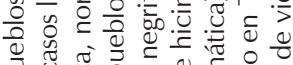

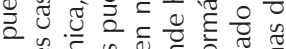

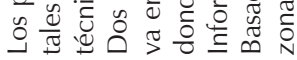




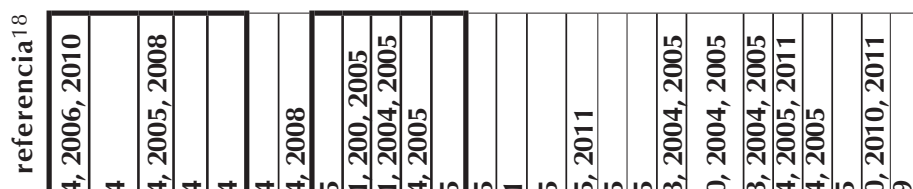

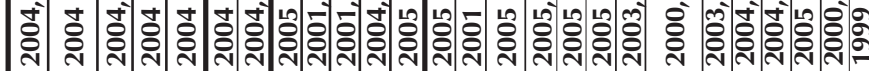

ำ

$\because$

楒山

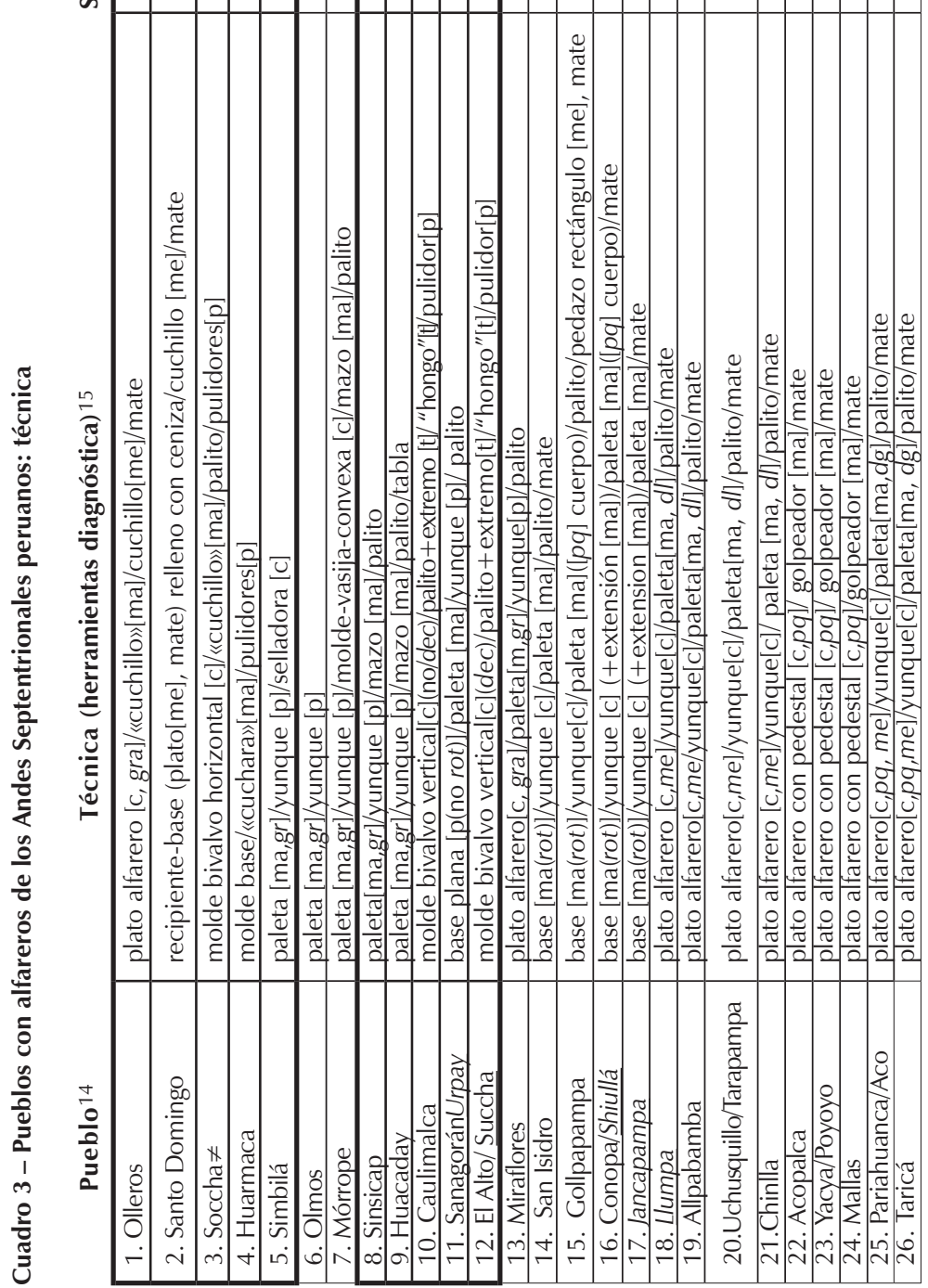

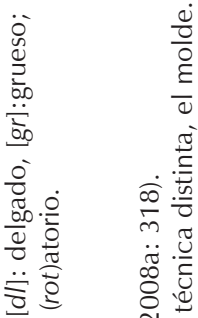

tᄒำ

\&ัँ

iृ

离额

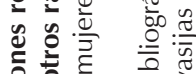

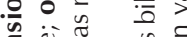

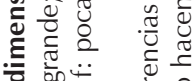

iृ

ป

ป .

证入

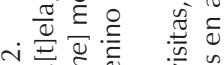

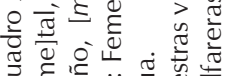

U ह

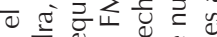

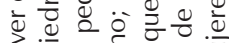
흐를

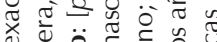

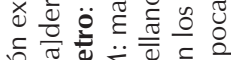

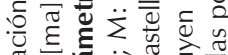
ช

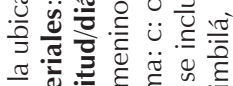
ฮั

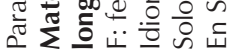


¿Porqué estudiar Conchucos? Primero, como indicamos, esta región tiene la mayor densidad de pueblos con alfareros en los Andes septentrionales peruanos [15-24]. Segundo, en comparación con otras áreas andinas, como la sierra piurana (Ramón, 2008b), la intersección entre áreas de distribución de vasijas es mayor. Lo sucedido en Conchucos se asemeja a lo reportado para Cuzco donde productos alfareros de diversos pueblos son ofrecidos en un mismo mercado (Rowe, 1944: 43; Mohr, 1984-1985: 184-188). Tercero, en Conchucos además de la intersección entre áreas de distribución de vasijas, las áreas de uso de fuentes de materias primas se superponen. Mientras en la sierra de Piura y La Libertad generalmente cada pueblo con alfareros tiene yacimientos en sus territorios, en Conchucos las mismas fuentes de arcilla y los otros materiales con los que se hacen las ollas, como la piedra pizarra (o sus equivalentes, ver adelante) pueden ser usadas por artesanos de diversos poblados. Cuarto, en esta región se ubica Allpabamba [19], una de las más notables fuentes regionales de arcilla en los Andes, junto con Mangallpa (Cajamarca), Mito Alto (Junín) y Córdova (Ica)20. El área de distribución de arcilla allpabambina es comparable - pero menor- a aquella de las salinas de Huacho (Lima) o San Blas (Junín), que han tenido un impacto continuo en los pueblos de sus alrededores (Middendorf, 1974 [1886], III: 73; Raimondi, 1873: 258-260). Gente de diversas zonas se desplazaba a estas canteras creando esferas de interacción humana. Sin embargo, una diferencia importante es que mientras la sal se desvanece en las comidas, en el caso de las materias primas para la alfarería, habría la posibilidad de trazar estos vínculos a partir de la composición, y —como enfatizaremos aquí- prestando mayor atención a las técnicas de manufactura.

Las primeras referencias publicadas sobre alfareros de Conchucos son del censo de 1876 (Censo general, 1878) (cuadro 4). Medio siglo después apareció un recuento comparativo de técnicas de manufactura alfarera peruana por Tello (1938: XIV-XVII). Este arqueólogo identificó solo un estilo técnico para Ancash, su denominada «Técnica Andina del Norte» que realmente se restringía a nuestro Conchucos central [18-21] y Taricá-Pariahuanca (Huaylas) [25-6]. Más allá de sus limitaciones, este estudio pionero brinda un indicio significativo para nuestros propósitos: todos los pueblos mencionados por este arqueólogo (Chacas [A], Llumpa [L], Piscobamba [L], Yauya [F]) utilizaban la misma técnica y se surtían de la misma cantera de arcilla, Allpabamba [19], que luego mezclaban con piedra pizarra para hacer sus vasijas (fig. 2)21. Más recientemente, desde los años 1990, Isabelle Druc ha realizado diversas investigaciones etnográficas entre los alfareros de Conchucos meridional y Chinlla [21] (Conchucos central) que brindan una

20 Sobre Mangallpa ver Ramón (2011: 167-8), sobre Mito Alto, O’Neale (1976: 55), sobre Córdova, Urbano \& Macera (1992: 41), y P. Macera (com. pers., 2010).

21 Inversamente al censo de 1876, Tello aludió a alfareras en Conchucos central. Actualmente, en los lugares mencionados por Tello, los alfareros son hombres y en los pocos pueblos donde solo mujeres hacen vasijas, ellas no usan las herramientas indicadas (paleta y broquel). Curiosamente, Tello no menciona Taricá [26] donde algunos alfareros son mujeres y usan esas herramientas, es decir el único caso que coincidiría con su descripción. Sobre Taricá ver Camino (1983) y Echeandía (1982). 
Cuadro 4 - Alfareros de Conchucos según el Censo de 1876 (Censo General, 1878)

Los distritos en negrita también aparecen en nuestra base de datos. La coincidencia es solo a nivel distrital, ya que el censo no alude a pueblos específicos. Actualmente Cajatambo pertenece al departamento de Lima y los distritos de Chacas y San Luis a Asunción y Fitzcarrald respectivamente

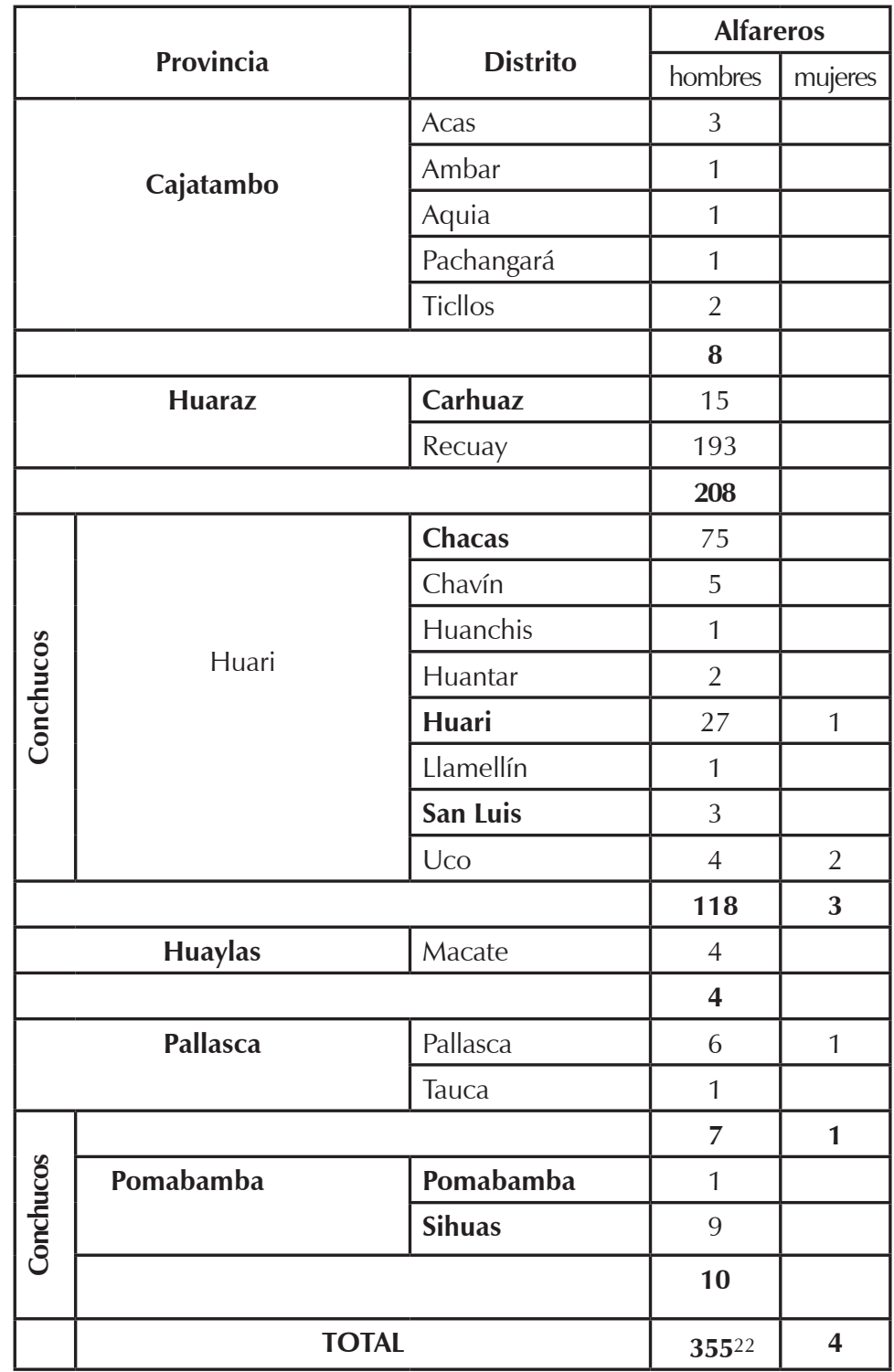

22 El total reportado para Ancash fue 435. En el distrito de Huaraz [Hu] 127 alfalferos (recolectores de alfalfa) son incluidos pero no alfareros. Tal vez un error tipográfico, ya que el pueblo con alfareros de Taricá [26] está en el área inmediata. 

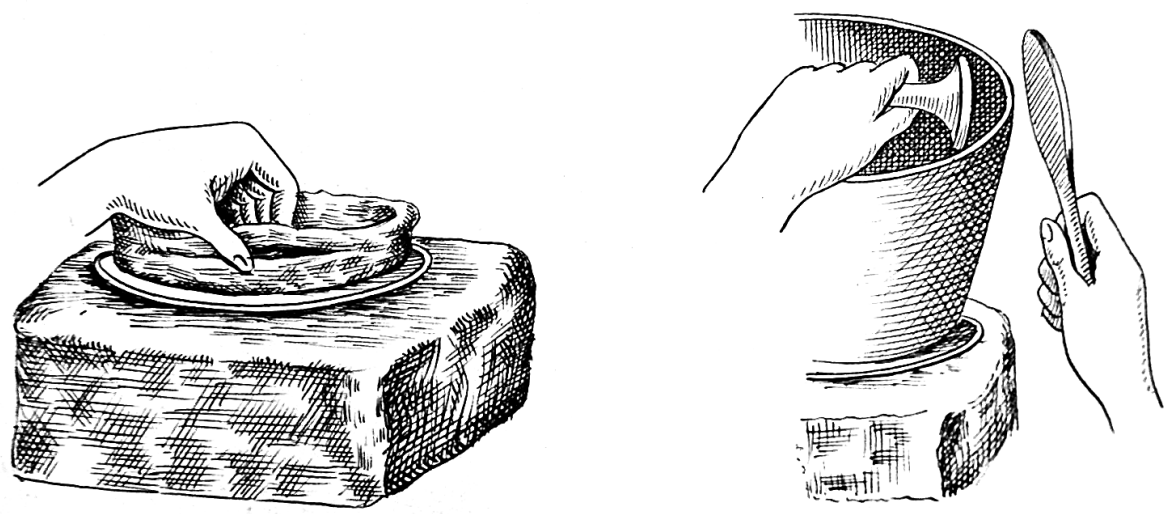

Figura 2 - La «Técnica Andina del Norte»

Identificada, según Tello (1938), en las provincias de Huari y Pomabamba, es decir todo Conchucos de acuerdo a la división política de entonces. Izq. formando la base en el plato de alfarero [tilla]. Der. paleta [material no especificado] y broquel [yunque de arcilla]

Archivo Julio C. Tello, Museo de Antropología y Arqueología, UNMSM

útil introducción a la cerámica de la región (Druc, 1996; 1998; 2000; 2005; ver mi reseña en Ramón, 2005). En este contexto, veamos lo que ha estado sucediendo con las materias primas y las técnicas en Conchucos meridional y central.

\section{CONCHUCOS MERIDIONAL [ACOPALCA, MALLAS, POYOYOC, YACYA]}

Cuatro pueblos con alfareras fueron identificados alrededor de la ciudad de Huari. Cuando realizamos las entrevistas $(2004,2005)$ dos de estas localidades tenían varias artesanas (Acopalca, $n=9$; Yacya, $n=20$ ), y en las otras la actividad se extinguía (Mallas, $n=3$, Poyoyoc, $n=3$ ) [22-24]23. En el siglo XIX, 28 alfareros (incluyendo una mujer) fueron identificados en el distrito de Huari (cuadro 4; Censo general, 1878, I: 15). Considerando la información disponible, la discusión se centra en los pueblos de Acopalca [22] y Yacya [23], con pocas referencias a Mallas [24] y al caserío de Poyoyoc [09 $24^{\prime} 04^{\prime \prime} \mathrm{S}, 077^{\circ} 10^{\prime} 15^{\prime \prime} \mathrm{O}, 3293 \mathrm{~m}$ ] (fig. 1). Estos cuatro lugares están separados pero conectados. Acopalca y Yacya están a dos horas a pie y la gente constantemente va de un lugar al otro: vimos vasijas de Acopalca siendo intercambiadas en Yacya, y alfareras yacyinas trabajando en Acopalca (Ramón, 2011: 165-6).

${ }^{23}$ Cabe indicar, que en varios casos las alfareras entrevistadas ya no ejercían su oficio. 


\section{1. Aprendizaje y práctica}

En Huari la transmisión del oficio ha sido entre mujeres: parientes, principalmente la madre, y/o una alfarera conocida. M. Inga [23] fue entrenada por su madre y su tía. L. Rojas [23] aprendió de su madre y también fue ayudada por una conocida (no pariente). No encontramos a personas de otros lugares que hayan aprendido y se hayan quedado en Yacya, pero sí algunas alfareras locales que hacen vasijas en otros poblados de los alrededores. En Acopalca, L. Castillo observó que durante su infancia mucha gente hacía ollas, y ella aprendió solo «mirándolas». Un ejemplo ideal de transmisión de conocimiento sería A. Zamudio [22]: entrenada por su madre quien hacía recipientes medianos y grandes, años después Zamudio instruyó a sus hijas, que solo han hecho vasijas medianas. En este proceso de aprendizaje, las herramientas alfareras son cruciales. F. Rojas [23] indica que su maestra —la madre de L. Rojas - acostumbraba vender herramientas a sus pupilos. En general, las tillas y las callhuas viejas sirven de prototipos y el entrenamiento no es en alfarería latu sensu sino en como usar un conjunto específico de instrumentos (fig. 3). Incluso cuando las alfareras viajan a otros caseríos a trabajar, Ilevan sus herramientas o trabajan con herramientas idénticas a las suyas. En Yacya y Acopalca, los hombres no intervienen en la manufactura alfarera, pero tienen un rol complementario: recolectan las materias primas, especialmente la piedra pizarra, ayudan a distribuir el producto y realizan la quema.

Las vasijas se hacen durante la estación seca, de abril a octubre/noviembre. Este periodo es ideal para el secado de la arcilla, para ir a las canteras, y para recoger combustible, principalmente bosta seca. Iniciando esa estación la producción se

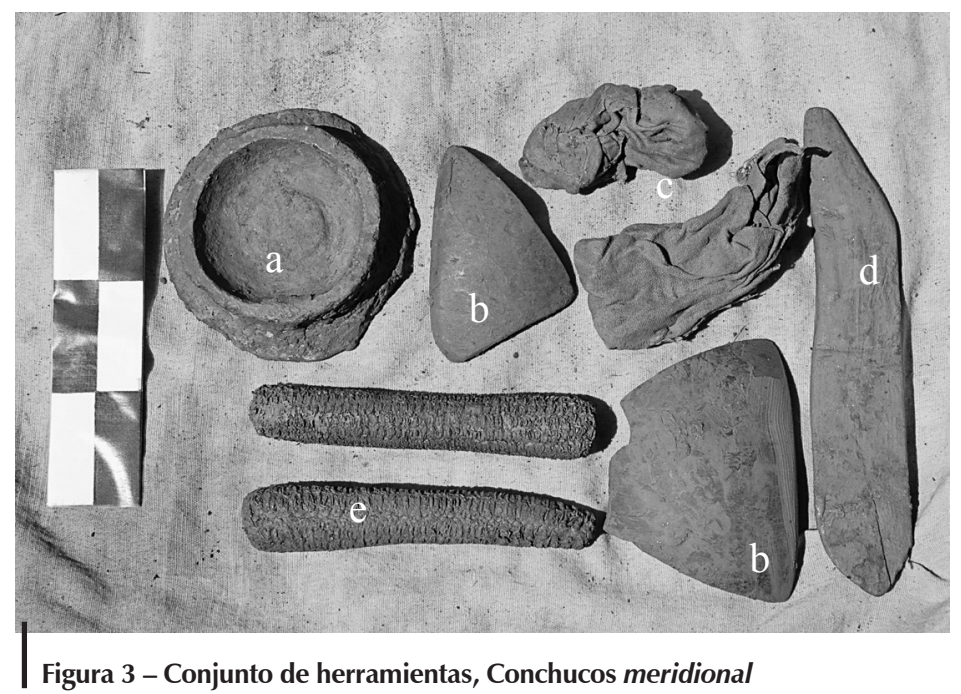

a. tilla [arcilla], b. gorgona [mate], c. shimina [tela], d. callhua [madera], e. goroshta [coronta]. F. Rojas, Yacya; escala $15 \mathrm{~cm}$

Foto: G. Ramón 
concentra en San Juan (24 junio) la principal festividad de Yacya y el periodo de cosecha de choclo (cuadro 5: seis de ocho alfareras trabajaban en junio). Si sobran vasijas, se les almacena. Como los periodos de cosecha pueden variar según el área y los productos, los campesinos llegan en diversas épocas a los pueblos con alfareros de Huari buscando vasijas. Entre estos pueblos, por su proximidad a la carretera (trazada en los años 1970), Acopalca ha incrementado su rol como lugar de almacenamiento y distribución de vasijas. Cuando la demanda es suficientemente alta, alfareros de Yacya son contratados en Acopalca. El segundo periodo de distribución va de fines de agosto a inicios de setiembre, para celebrar los festivales en Acopalca (23 de agosto, San Bartolomé) y Yacya (8 de setiembre, Virgen de la Natividad). Las alfareras vuelven a trabajar en agosto acumulando vasijas para estas fiestas cuando gente de todos los caseríos de Huari llega a ambos pueblos (cuadro 5: siete alfareras de ocho trabajaban en agosto). Posteriormente, la producción se centra en las celebraciones por Todos los Santos.

\section{Cuadro 5 - Alfareros, agricultura y manufactura alfarera en Huari, Conchucos meridional}

Los meses van indicados por sus iniciales. x: producción alfarera. Información proporcionada por S. Yauri (Acopalca) y los alfareros incluidos en Apéndice 1

\begin{tabular}{|c|c|c|c|c|c|c|c|c|c|c|c|}
\hline \multirow{3}{*}{$\begin{array}{l}\text { mes } \\
\text { E-M }\end{array}$} & \multirow[b]{3}{*}{ Iluvia } & \multirow[t]{3}{*}{ siembra } & \multirow[t]{3}{*}{ cosecha } & \multicolumn{8}{|c|}{ manufactura alfarera } \\
\hline & & & & \multicolumn{3}{|c|}{ Acopalca } & \multirow{2}{*}{$\begin{array}{c}\text { Poyoyoc } \\
\text { T.Z } \\
\end{array}$} & \multicolumn{4}{|c|}{ Yacya } \\
\hline & & & & L.C. & F.T & A.Z. & & M.I. & A.R. & F.R. & L.R. \\
\hline A & \multirow{7}{*}{ 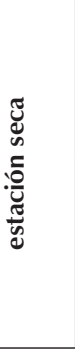 } & & maíz, oca, & & & & & $x$ & & & \\
\hline$M$ & & oca & olluco, papa & & & & & $x$ & $x$ & $x$ & \\
\hline J & & \multirow[t]{3}{*}{ papa } & $\begin{array}{c}\text { maíz, olluco, } \\
\text { papa, trigo }\end{array}$ & & & $\mathrm{x}$ & $x$ & $\mathrm{x}$ & $\mathrm{x}$ & $\mathrm{x}$ & $\mathrm{x}$ \\
\hline J & & & cebada, & $x$ & & $x$ & $x$ & $x$ & & & \\
\hline A & & & $\begin{array}{l}\text { chocho, } \\
\text { trigo }\end{array}$ & $x$ & $x$ & $\mathrm{x}$ & $\mathrm{x}$ & $x$ & $\mathrm{x}$ & & $\mathrm{x}$ \\
\hline $\mathbf{S}$ & & maíz, olluco & & & $x$ & $x$ & $x$ & $x$ & & $x$ & \\
\hline $\mathbf{O}$ & & maíz, papa & & & $x$ & $x$ & & & & & \\
\hline N-D & Iluvia & $\begin{array}{c}\text { cebada, papa, } \\
\text { trigo }\end{array}$ & & & & & & & & & \\
\hline
\end{tabular}

\section{2. Canteras}

En Huari, las alfareras combinan dos materiales para hacer sus ollas: arcilla y un tipo de piedra pizarra. Para la arcilla [racu] ellas principalmente usan dos fuentes, ambas en Yacya: Cayash para los yacyinos, y Pariacucro para los acopalquinos (para yacimientos y usuarios ver figura 4 y cuadro $6: \mathrm{a}$, b). Los alrededores del pueblo de Yacya son un gran depósito de arcilla, disponible en todas las chacras circundantes. Todas las canteras de piedra pizarra [shashal, lombagina o grafito, en Huari] están en la puna oeste en el territorio de Acopalca: los yacyinos usan principalmente Cayash (homónimo con la cantera de arcilla pero ubicada sobre los $4000 \mathrm{~m}$ ) y los alrededores de la laguna de Ishkaycocha (cuadro 6: c). Los acopalquinos extraen shashal de Jacabamba (opuesto a Cayash, en el mismo 
Gabriel Ramón

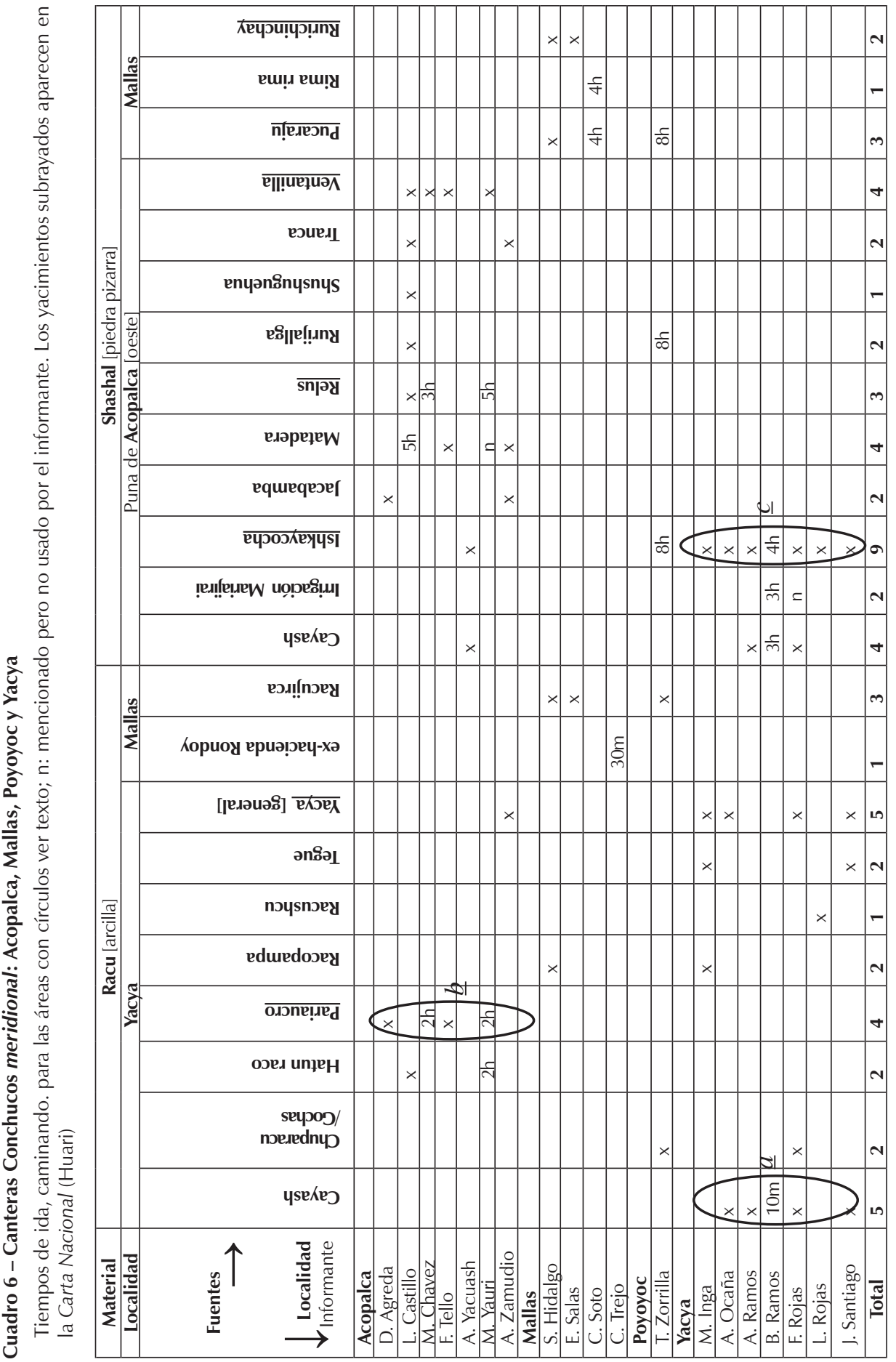




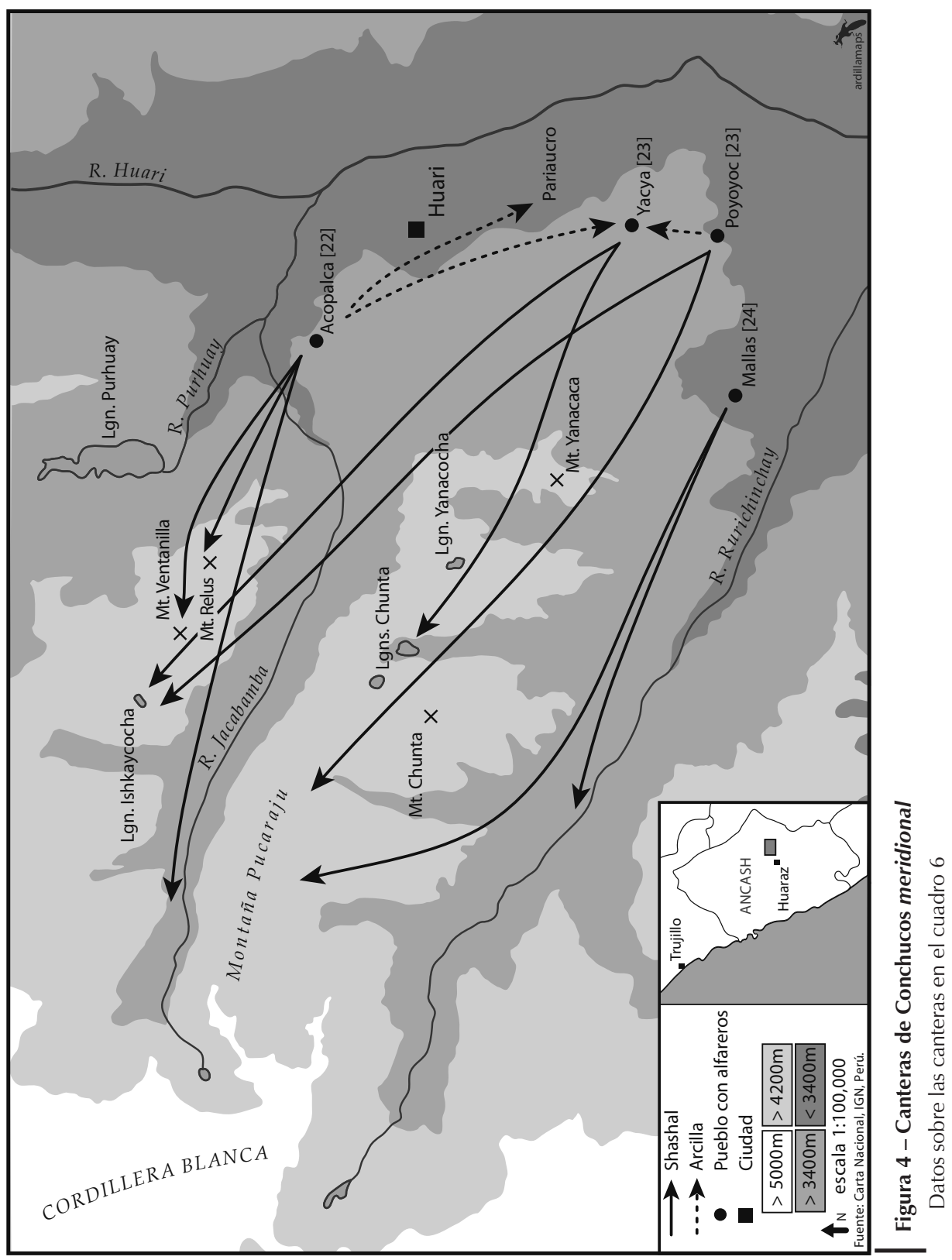


pico), Matadera y Ventanilla. Los artesanos de Mallas y Poyoyoc tienen sus propias canteras, ubicadas alrededor de Mallas: la arcilla está próxima y el shashal en la puna, al oeste de Mallas. Los yacimientos de arcilla y piedra pizarra están distribuidos en el paisaje según principios geológicos, sin embargo, el modo en que son explotados refuerza los vínculos entre los pueblos con alfareros huarinos. En este circuito la interacción social se hace rutina, lo que permite esperar otros rasgos semejantes entre ambos pueblos, como el estilo técnico, por ejemplo24.

En Huari la recolección de materias primas, especialmente del shashal, es actividad masculina. Para alcanzarlo se organizan pequeñas expediciones conformadas por varios hombres con sus burros. El viaje de ida tarda de tres a ocho horas, dependiendo de la ubicación. Estos viajes son principalmente realizados en la estación seca para evitar las lluvias y los rayos que incrementan las dificultades en el camino. El proceso de extracción se hace con barras de metal (1 m), y luego de comer y dormir por los alrededores, vuelven a casa de madrugada. Debido a su proximidad (alrededor de Yacya) la arcilla puede extraerse diariamente, luego de haber concertado con el dueño. Los yacyinos generalmente tienen su propia cantera de arcilla, o solo deben pedir permiso a sus vecinos. Los acopalquinos pagan en especies o dinero por la arcilla: A. Zamudio [22] acostumbraba cambiarla por maíz o vasijas. En Poyoyoc hay una cantera de arcilla local pero T. Zorrilla y su marido prefieren recolectarla en Yacya, pagando en vasijas al dueño. Durante la estación seca, el mejor tiempo para extraer arcilla es entre agosto y octubre, ya que en los otros meses las fuentes son usadas como chacras. Se nos indicó que años atrás, algunas personas sembraban papa cerca del yacimiento de shashal, pero sin interferir con la recolección del material25. Comparando la ubicación de ambos tipos de canteras (racu y shashal), parece que sus distancias a los pueblos se relacionan con su régimen de propiedad. La división de la tierra es más rigurosa a medida que uno se aproxima a los centros poblados, por tanto las fuentes de racu están en manos privadas o de comunidades definidas. Mientras tanto las lejanas canteras de shashal son comunales y no se requiere permiso específico para utilizarlas, pero — como veremos - hay que consultarle a María Jirai.

El par racu/shashal es unánimemente reconocido en Conchucos meridional, e incluso se hacen mayores distinciones. Por ejemplo, B. Ramos mencionó tres yacimientos de distinto racu, a menos de diez minutos del centro de Yacya: Cochapucro (gris), Jamalyanga (rojo) y Shushumbia (caoba). En el mismo pueblo, F. Rojas mezcla tres tipos de arcilla: Comuningiño (marrón), Callaun (rojo) y Wachujotju (rojo). Ella combina dos variedades de shashal: Cayash (más firme y brillante) e Ishkaycocha (morado-rojo). El nivel más refinado de discriminación se hace en la cantera misma: en Mullipampa, A. Ramos [23] nos explicó las calidades de los estratos de acuerdo a su apariencia y textura (fig. 5).

24 Los nombres quechua de las materias primas son compartidos entre los pueblos con alfareros de Conchucos meridional y han dejado su impronta en la toponimia: cinco de las ocho fuentes de racu incluyen este término en sus nombres (cuadro 6) y el valle por donde la mayoría de los alfareros transita para llegar a las fuentes de shashal, es irrigado por el río homónimo.

25 En los Andes sur-centrales (Huancavelica), Raimondi (1929: 18) notó que las tierras con piedra pizarra producían papas de alta calidad. 


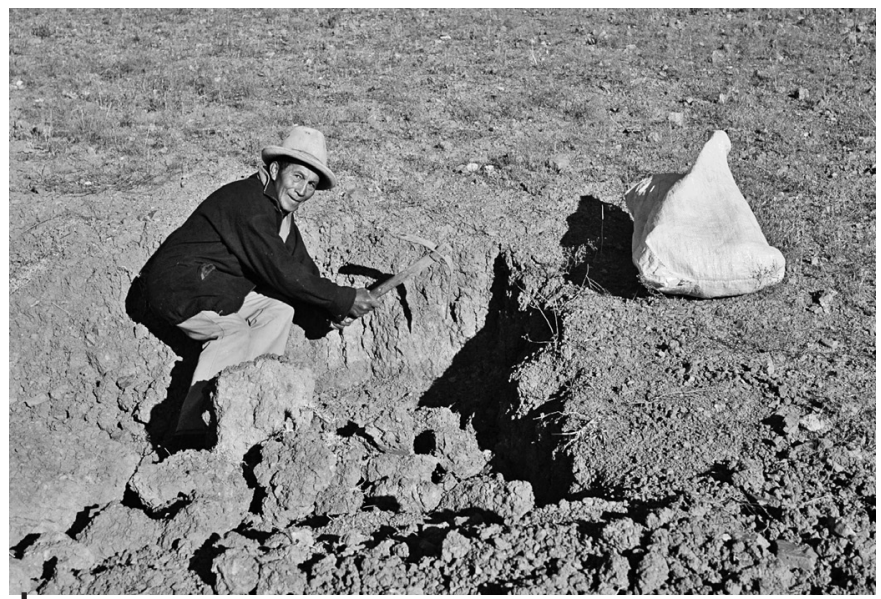

Figura 5 - Yacya. A. Ramos extrayendo arcilla de Mullipampa, Cayash (agosto de 2004)

El lugar sirve de chacra durante la estación húmeda

Foto: G. Ramón
En Conchucos meridional las proporciones de materia prima usadas por las alfareras son similares: dos unidades de racu por una de shashal. No obstante, algunas personas añaden más de lo último: M. Inga [23] combina cantidades equivalentes, mientras que A. Ramos [23], once de racu por nueve de shashal. F. Rojas [23] observó que la mezcla siempre incluye más racu, pero se hace como regateando en el mercado: se inicia con proporciones similares, y uno va agregando el garayni o yapa, llegando a cerca de dos de racu por una de shashal. Esta variabilidad en las proporciones

entre ambos pueblos se vincula con la diversidad en la composición de cada tipo de yacimiento: especialmente a las diferencias entre el shashal de Ishkaycoha, usado casi exclusivamente por los yacyinos, y las otras canteras (cuadro 6: c)26.

Arcilla y shashal son molidos por hombres en el marey con una piedra amarrada a un palo (tuñey), un tipo de herramienta presente más al norte en Conchucos y en Huaylas (e.g. en Hualcán [Hu], Stein, 1961: 94 y Chinlla [21]) (fig. 6). Luego de mezclar ambos ingredientes, añadirles agua y pisarlos, el resultado se almacena. Como podemos observar, desde la extracción

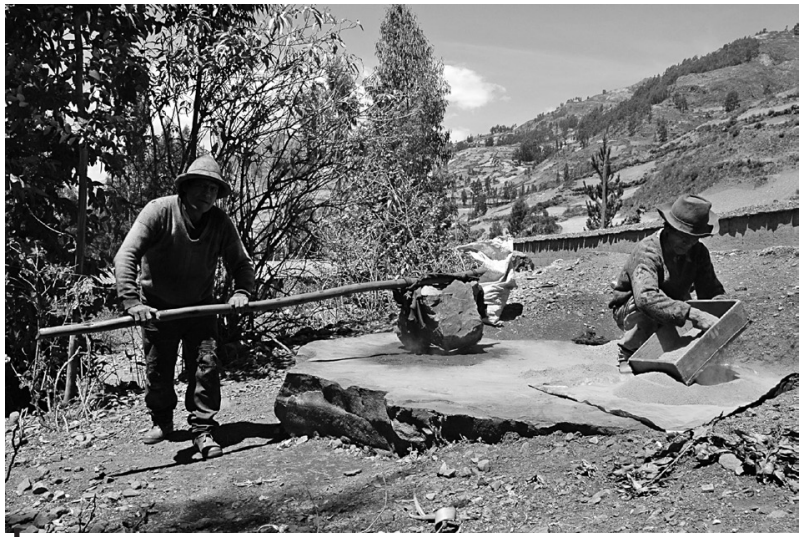

Figura 6 - Acopalca. Marcelino Rodríguez moliendo shashal en el tuñey/marey, Santos Yauri colando el racu ya molido (setiembre 2005) Foto: G. Ramón

26 Las observaciones previas respecto a la variedad de materias primas reconocidas y empleadas por los huarinos obligan a referirnos a la propuesta de Druc (2000: 169-70) para definir geológicamente el shashal. Basándose en muestras $(n=6)$ de este material provenientes de Acopalca [22], Yacya [23] y Chinlla [21], ella observó que según la localidad, este material contiene diversa cantidad de carbón. Como bien señala esta autora su denominación precisa debería considerar esa diferencia: por ejemplo, en Acopalca tendríamos que decir ignita (ca. 50 \% de carbón) y en Chinlla lutita negra (menos de 2 \% de carbón). La variabilidad descrita por los usuarios sugiere que a la diferencia geológica detectada por Druc entre los pueblos cabe agregar la existente entre canteras en cada uno de los pueblos. Por ejemplo entre las variedades de Cayash e Ishkaycocha. Y algo semejante sucede en Conchucos central (ver sección 4. 2). 
de las materias primas en el yacimiento hasta cuando la masa está lista para convertirse en vasija, toda una serie de transformaciones y selección de opciones técnico-culturales ha estado presente. Se trata de un trayecto multidimensional acompañado por creencias a las que conviene referirse brevemente.

\section{3. Materiales y rituales}

Como hemos visto, en Conchucos meridional hay dos tipos de yacimientos ubicados a diferentes altitudes: shashal en la puna, y arcilla en la quechua. Cuando la fuente es cercana, como en el caso de la arcilla, hombres y mujeres pueden extraerla, pero si el lugar es más remoto el acceso se complica, como sucede con el shashal, al que se asocian ciertos ritos. En los tres pueblos donde se nos informó de colapsos fatales en las minas de shashal (Acopalca, Yacya, y Chinlla) la gente continúa haciendo ofrendas. El peligro diferencial se asocia a la altitud, y a la ubicación específica de la cantera. Las de shashal normalmente están en las faldas de los cerros, y son cavadas lateralmente creando pequeñas cuevas, con derrumbes frecuentes. Mientras tanto, la arcilla está en terrenos planos, excavados verticalmente, que cada año son nivelados por las lluvias. En Huari, si la extracción de arcilla se hace en grupo, el beneficiario retribuirá a sus asistentes, pero sin ningún ritual especial a la cantera. Las características mencionadas nos permiten entender el prestigio diferencial de ambas fuentes en Conchucos meridional, y por qué el discurso ritual se vincula al shashal (cuadro 7)27.

Al preguntarle sobre los yacimientos de shashal, A. Ramos [23] indicó que ellos lo extraen de la laguna de Chuntacocha «donde vive María Jirai» (fig. 4). El valor de los yacimientos de shashal para las comunidades de Conchucos meridional ha

\section{Cuadro 7 - Conchucos meridional}

Diferencias entre fuentes de arcilla y shashal

\begin{tabular}{|l|c|c|}
\hline \multicolumn{1}{|c|}{ rasgos } & racu [arcilla] & shashal [piedra pizarra] \\
\hline Nivel ecológico & quechua & jallca/puna \\
\hline Ubicación específica & horizontal & vertical \\
\hline Intervención (excavación) & vertical & horizontal \\
\hline Peligro potencial & bajo & alto \\
\hline Uso como chacra & frecuente & raro \\
\hline Propiedad & privada/comunal & comunal \\
\hline Ritual & ausente & presente \\
\hline
\end{tabular}

27 Antes que el propio material, son sus rasgos asociados los que le otorgan peso ritual. Como se verá, en Uchusquillo [20] donde la piedra pizarra está al nivel del pueblo y es de fácil acceso, ninguna ceremonia es mencionada, y al contrario en Conopa [16], donde la fuente de arcilla está en la puna, algunos rasgos sobrenaturales fueron atribuidos a ella (ver adelante). 
dejado huella en la leyenda de María Jirai sobre los orígenes de Yacya y Huari. Este relato describe una competencia entre ella y otros tres personajes para construir una iglesia que consagraría su sede como el lugar más importante de la provincia: en Huari dicen que María Jirai construyó su iglesia, en Yacya la de ellos. Tras su victoria María se resintió, y huyó a la puna, lanzándose dentro de la laguna de Chuntacocha en el área donde están las canteras de shashal28. Hoy en día cuando alguien llega a estas fuentes de shashal, «Tiene que cariñarla [a María Jirai] con cigarro, alcohol, fruta» (A. Ramos). En caso contrario, María «los hace soñar» sugiriéndoles qué producto llevar. A menos que ellos sigan sus deseos, el shashal se moverá. Mejor dicho, la cantera solo se aparecerá a quienes la consuelan [shoga pagcunata yuripan veta] (C. Ramos, [23]).

En general, como cualquier otro recurso natural de puna, el shashal pertenece a la montaña y el ritual funciona como una serie de reglas, que la gente sigue cuando usa el lugar, para preservarlo. María Jirai forma parte de una categoría mítica observada a lo largo de los Andes, pero su relato está imbricado en la topografía de Huari. Solo en Conchucos meridional las minas de shashal usadas para la alfarería están en la puna alta: cuando avanzamos hacia el norte, estas canteras se ubican más abajo y María Jirai desaparece.

\section{4. La impronta técnica}

La información presentada ilustra cómo, incluso antes de la manufactura, hay interacción social relacionada con las materias primas entre los pueblos con alfareros de Huari. Cada vasija (una mezcla de racu y shashal) materializa la relación constante entre los dos pueblos principales y los dos niveles ecológicos (quechua y puna). La semejanza del producto final de estos pueblos no se restringe al ámbito geológico. Las prácticas y el conocimiento relacionados con el procesamiento de materias primas, su nomenclatura, y los rituales en relación con las fuentes forman una base cultural compartida entre estas comunidades. Esto se manifiesta también en el estilo técnico [22-4] común adquirido a través de un proceso de aprendizaje dentro del contexto de cada uno de estos pueblos.

Esta serie de rasgos compartidos puede ser reconocida en los detalles formales de las vasijas. Por ejemplo, todas ellas, desde los grandes recipientes para preparar chicha [aswana] a la popular olla mediana [manca], tienen una base relativamente plana y pequeña respecto al cuerpo (fig. 7). Esta es la huella más evidente del diminuto y casi no-rotatorio plato de alfarero con pedestal [tilla], exclusivo de Conchucos meridional29. En promedio, la tilla de Huari es la menor en su categoría

28 Los alfareros, tamberos y personas locales conocen este relato. Hemos oído versiones de tres lugares distintos: A. Ramos [23], A. Zamudio [22] y Ricardo Ibarra (ciudad de Huari).

${ }^{29}$ Decimos 'diminuto' y 'no-rotatorio' en relación con el instrumento de la misma categoría (plato alfarero) en Conchucos central y septentrional. También en relación con el lugar con alfareros más cercano documentado hacia el sur (Santo Domingo de los Olleros, Huarochirí, Lima, Ramón, 1999: 228-9). 


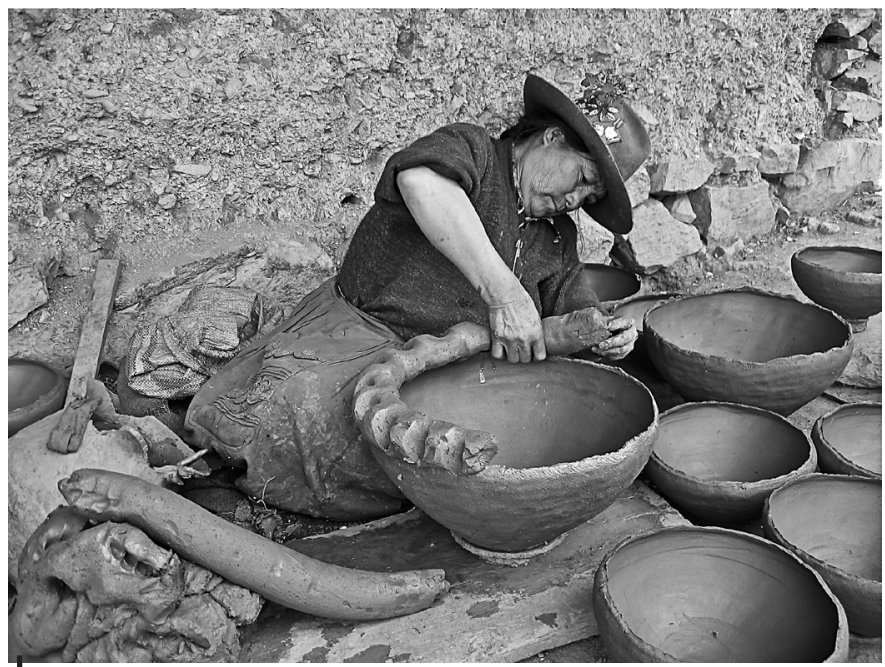

Figura 7 - Felicita Rojas (Yacya) haciendo ollas en Acopalca

Foto: J. L. Pino (la secuencia completa en Ramón, 2008a: 403-405; 2011: 166)

en Conchucos, con un rango de 9 a 15 cm30. Este margen varía en relación con el producto esperado, siendo las tillas mayores aquellas para las aswanas y las tinajas, y aquellas para uyllus o jarras los menores (fig. 8). La segunda herramienta diagnóstica de las alfareras huarinas es la callhua, de aliso o eucalipto, así llamada por su semejanza formal con el instrumento usado por los tejedores para ajustar los hilos, el golpeador (fig. 3 d). No podemos discutir aquí los otros rasgos particulares vinculados a este grupo de herramientas y los productos alfareros, pero la pequeña base plana de las vasijas es suficiente para percibir la asociación concreta entre las canteras y la distribución de un estilo técnico específico. Ya que el caso de Conchucos meridional podría ser considerado excepcional, veamos el siguiente.

\section{CONCHUCOS CENTRAL [ALLPABAMBA, CHINLLA, LLUMPA, UCHUSQUILLO]}

Treinta kilómetros al noroeste de Huari está el pueblo de Chinlla [21]. Dieciséis kilómetros más al norte Allpabamba [19] y Uchusquillo/Tarapampa [20], separados por el estrecho valle formado por un ramal del río Yanamayo (fig. 1). Ocho kilómetros más al norte se ubica Llumpa [18]. Estos cuatro pueblos de alfareros tienen dos cosas en común: el estilo técnico y una fuente de arcilla31.

30 Observación basada en el siguiente rango de tillas. En Acopalca: D. Agreda, 10,5-15 cm ( $n=13)$; L. Castillo, 11-14,5 cm ( $n=9)$. En Yacya: M. Inga, 10-13 cm ( $n=4) ;$ F. Rojas, 9-15cm $(n=31)$.

31 Además de los pueblos aquí mencionados uso los datos de un reporte de Tello (1920) sobre materias primas del pueblo de Llama [L] (fig. 1). 


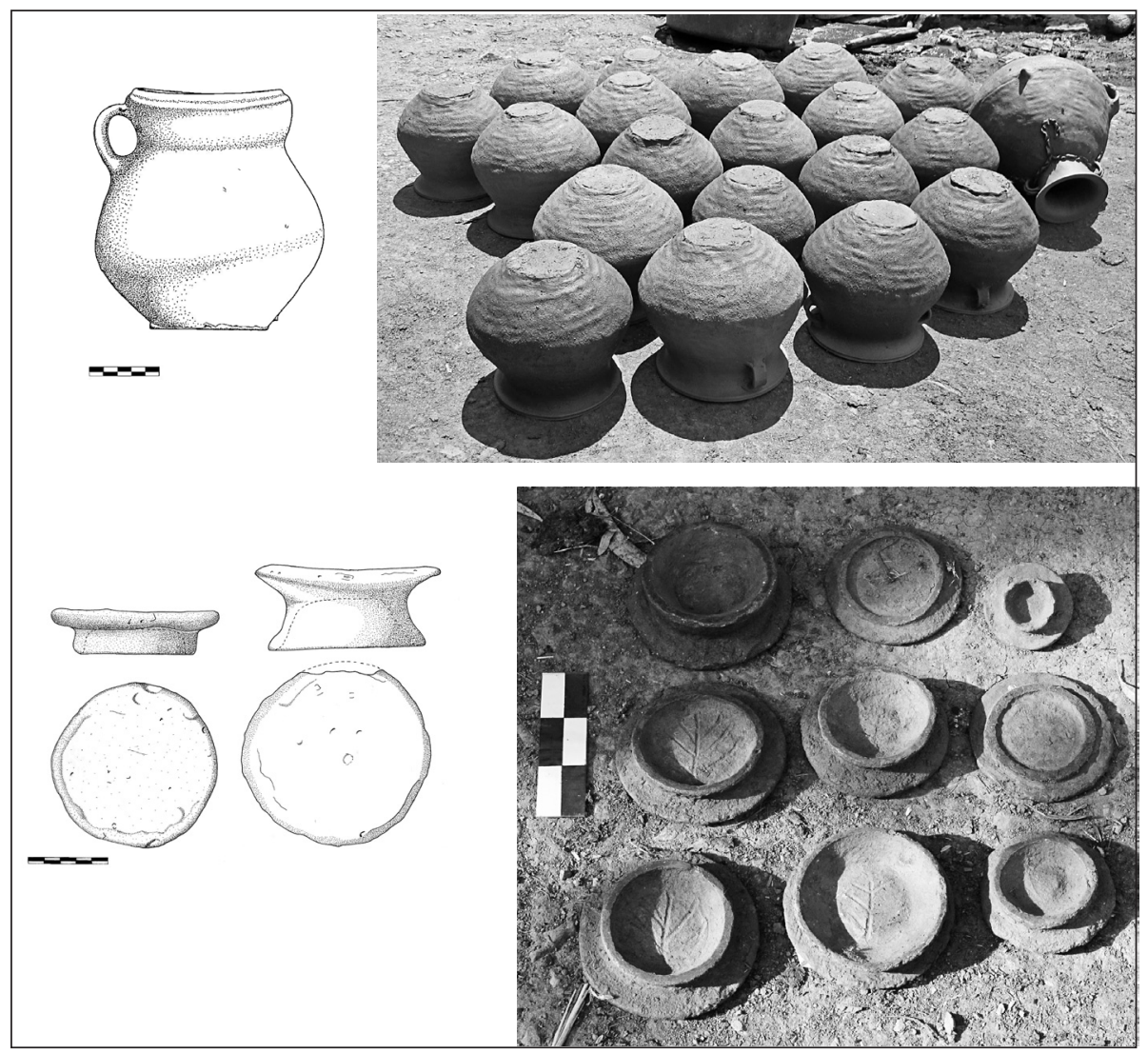

Figura 8 - La impronta de la tilla en Concuchos meridional

En sentido horario: manka, M. Ynga (Yacya), escala $5 \mathrm{~cm}$; mankas, boca abajo, y un uyllu (extrema derecha), hecho en Acopalca por F. Rojas (Yacya); nueve tillas, con la base hacia arriba, L. Castillo (Acopalca), escala $15 \mathrm{~cm}$; tillas, izq. F. Rojas (Yacya); der. A. Zamudio (Acopalca), escala $5 \mathrm{~cm}$. Fotos: G. Ramón

A los productos cerámicos de Chinlla se les denomina chacasinos y a las ollas chacasmanca ya que su principal centro de distribución ha sido Chacas, la capital provincial y la ciudad más próxima a Chinlla $(1$ h). El censo de 1876 registra 75 alfareros (hombres) en Chacas (cuadro 4). La primera alusión al oficio en Chinlla es de los años 1940, y puede documentarse al menos desde inicios del siglo veinte (Márquez, 1965 [1946]; el abuelo del informante G. Cruz [n. 1960], era alfarero). Chinlla tiene dos áreas principales: Hatun, la sección urbana, e Ichiq, formada de casas desperdigadas en una zona escarpada, que aloja a la mayoría de alfareros ( $n=12$; cuadro 8) en sus barrios y alrededores (San Bartolomé, Huayush, Gachir). Al menos desde el siglo XIX, Uchusquillo y Allpabamba fueron haciendas. En Uchusquillo tal sistema concluyó con el levantamiento de 1952-1953 y en Allpabamba luego de la Reforma Agraria (fines de los años 1960). Allpabamba [pampa de arcilla, en quechua] ha sido conocida como cantera regional, al menos 
Cuadro 8 - Fuentes de materias primas usadas en Chinlla, Conchucos central

Aureliopucro y Huaripampa pertenecen a Huaychao. Este último es mencionado cuando la ubicación no es especificada. Los tiempos indican el viaje de ida y vuelta; a Allpabamba con burros

\begin{tabular}{|c|c|c|c|c|c|}
\hline \multirow[b]{2}{*}{ Alfarero [caserío] } & \multicolumn{4}{|c|}{ Shashal [piedra pizarra] } & \multirow{2}{*}{$\begin{array}{c}\text { Allpa [arcilla] } \\
\text { Allpabamba }\end{array}$} \\
\hline & Huaychao & $\begin{array}{c}\text { Aurelio- } \\
\text { pucro }\end{array}$ & Huaripampa & Otro & \\
\hline M. Almanza [Gachir] & $2 \mathrm{~h}$ & & & & $10 \mathrm{~h}$ \\
\hline G. Cruz [Huayush] & & & $x$ & & $x$ \\
\hline J. Laveriano [Gachir] & & & $x$ & & $x$ \\
\hline R. Minaya [Huayush] & & $20 \mathrm{~m}$ & $x$ & & $x$ \\
\hline L. Padilla [Ututugocha] & & & $1 \mathrm{~h}$ & Paria & $x$ \\
\hline O. Ríos [Ichiqchinlla] & & & $\mathrm{x}$ & $\begin{array}{c}\text { Potrero, } \\
30 \mathrm{~m}\end{array}$ & $\begin{array}{c}\text { Allpashpina, } \\
30 \mathrm{~m}, \mathrm{x}\end{array}$ \\
\hline V. Ríos [Hatunchinlla] & $2 \mathrm{~h}$ & & & & $x$ \\
\hline Co. Rivera [Huayush] & $x$ & & & & $x$ \\
\hline Cl. Rivera [Gachir] & $x$ & & & & $x$ \\
\hline C. Rodríguez [Ututugocha] & & & & Lloglla & $10-12 \mathrm{~h}$ \\
\hline C. Sifuentes [Huayush] & $30 \mathrm{~m}$ & & & & $12 \mathrm{~h}$ \\
\hline L. Vega [S.Bartolomé] & & $x$ & $1 \mathrm{~h}$ & Potrero & $12 \mathrm{~h}$ \\
\hline
\end{tabular}

desde el reporte de Tello (1938: XIV). Uchusquillo pertenece al distrito de San Luis donde tres alfareros fueron reportados en 1876 (cuadro 4). Actualmente hay alfareros activos en ambos pueblos (Allpabamba, $n=8$, Uchusquillo, $n=18$ ) y lugares aledaños (Tarapampa, $\mathrm{n}=8$, Ishanca, $\mathrm{n}=2$ ).

\section{1. Aprendizaje y práctica}

En Conchucos central, el oficio es transmitido entre hombres, principalmente parientes. En Chinlla [21], G. Cruz, corresponde al esquema tradicional: su padre y abuelo fueron alfareros, y él aprendió a los catorce años. J. Laveriano dice que su familia trató de contratar a un alfarero para ellos, pero como nunca llegó, él comenzó a hacerlas por sí mismo. Un alfarero (anónimo requerido) nació en otra región y llegó joven a Chinlla, donde conoció a su futura esposa. Él acostumbraba viajar con su suegro para intercambiar vasijas y desde los años 1970 comenzó a hacer ollas utilizando las herramientas de su suegro. En Allpabamba [19] y Uchusquillo [20] el patrón es semejante, pero además de los parientes mayores, los alfareros suelen mencionar otras fuentes de aprendizaje como los artesanos contratados para trabajar en casa del potencial pupilo. E. Moreno [20] bebió de ambas fuentes. J. García [19] aprendió de su padre hacia 1993, y una década después instruyó a su sobrino N. Tarazona. Este último también era entrenado por A. García, quien — décadas antes — había aprendido «mirando» a otros alfareros locales. Como en Huari, los artesanos de Conchucos central resumen el proceso de aprendizaje con ese verbo. Hemos observado parte del mismo en Allpabamba: A. García estaba 
enseñando a R. Arellano, cuyo fallecido padre fue alfarero. Por algunas sesiones ellos trabajaron juntos en casa de Arellano, quien imitaba al maestro, pero solo hacía vasijas pequeñas. Arellano también se encargaba de todo el trabajo complementario: recolectar y procesar las materias primas, y pulir las vasijas (fig. 9).

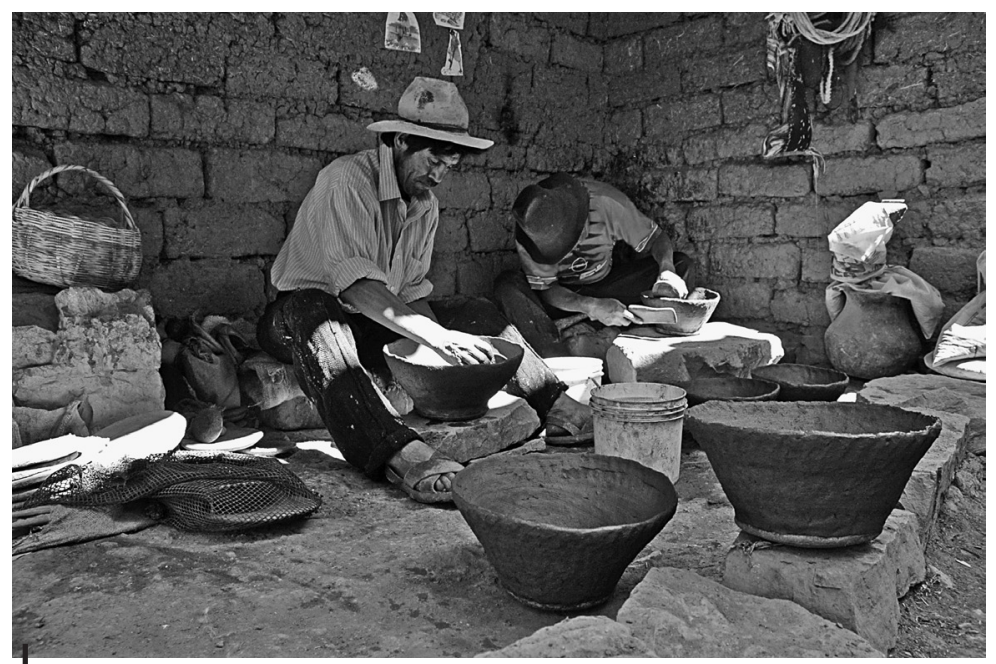

Figura 9 - Allpabamba. Ramón Arellano paleteando, aprendiendo de Alfonso García, con sombrero blanco

Foto: G. Ramón
Todos los casos registrados en Conchucos central siguen un mismo estilo técnico. Incluso aquellos alfareros que dijeron haber aprendido por sí mismos hacen las ollas en la misma forma y con instrumentos similares. Los alfareros nacidos en otras áreas pero residentes en Conchucos central siguen un patrón semejante. El caso de W. Carrión [19] es ilustrativo: aprendió de un alfarero de Mismi (Sapchá, 2,5 $\mathrm{h}$ al sur de Allpabamba) (fig. 10) quien acostumbraba trabajar en su casa. Luego, el propio Carrión ha ido a

hacer vasijas en Sapchá, donde las personas del lugar le prestan las herramientas. Sapchá y Allpabamba comparten un mismo estilo técnico. Las mujeres tienen un rol complementario, ellas pueden ayudar recolectando y procesando el material, y bruñiendo las vasijas. En Conchucos central son los propios alfareros quienes controlan la quema.

En Conchucos central, se ejerce la alfarería durante la estación seca, entre abril y diciembre. En Chinlla, J. Laveriano acostumbraba hacer vasijas entre mayo y setiembre, ya que en época de lluvias, «el barro no se para» [sharentaku piru mitu tacyantzu jagyantzu]. Como en Conchucos meridional las vasijas se hacen para obtener comida por intercambio y los alfareros necesitan tener sus productos listos para la cosecha (que puede variar según el producto y su ubicación) y las fiestas intercomunales. Por ejemplo, en septiembre (2005) L .Vega [21] ya había quemado tres veces (mayo, junio, agosto) y estaba haciendo vasijas para la fiesta de San Miguel (29 de setiembre), celebrada en el poblado homónimo cercano. Después de todo esto, Vega todavía necesitaba sembrar maíz.

\section{2. Canteras}

Según el relato La maldición del Inca, este soberano solicitó a los chinllinos otorgarle algunas de sus mujeres para su servicio. Desairado por los chinllinos, el Inca los castigó lanzando shashal a sus chacras, haciéndolas menos productivas, y 


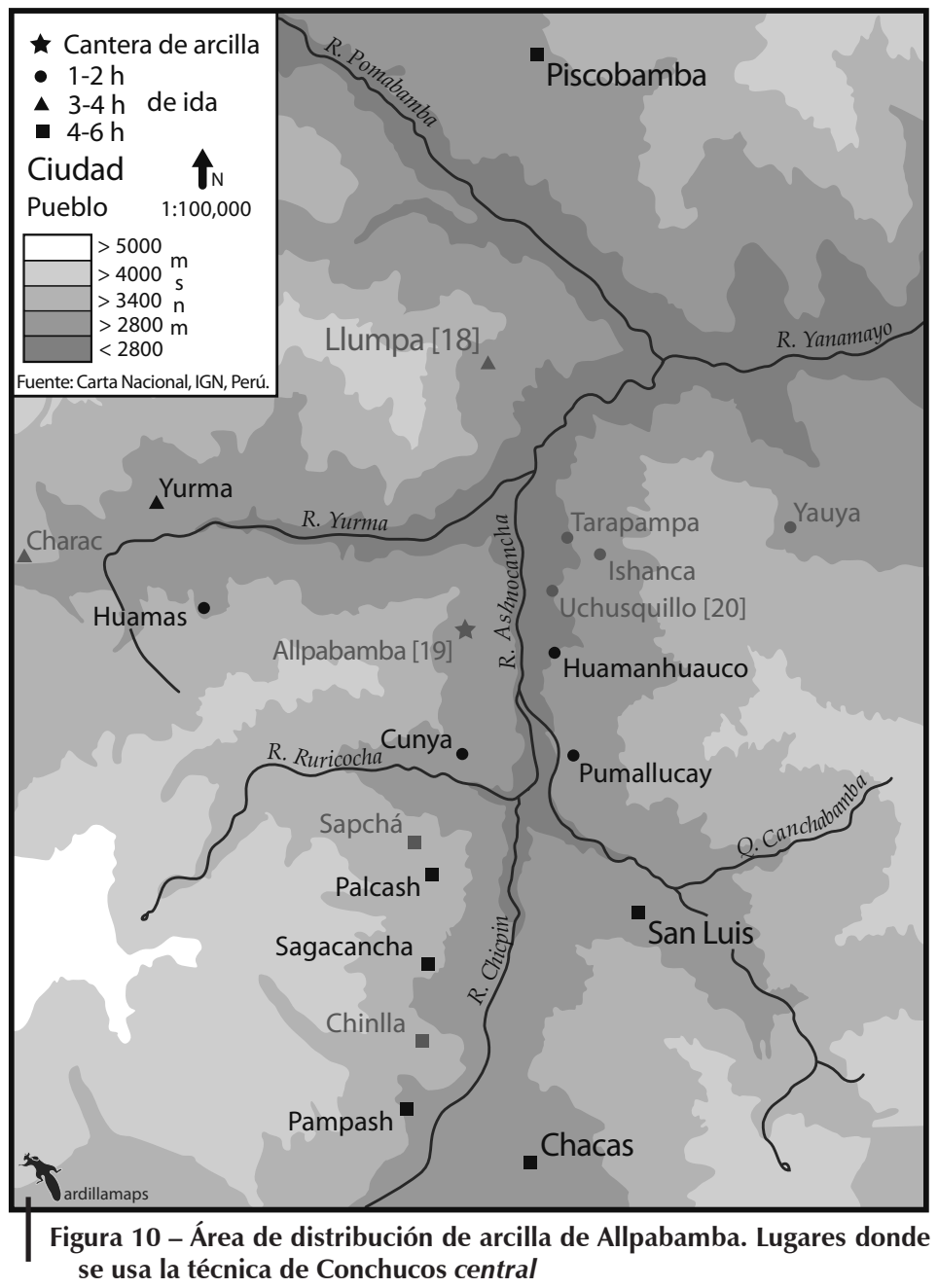

La información sobre la duración de los viajes fue obtenida en Allpabamba

lanzando arcilla sobre Allpabamba. Mientras tanto, el soberano premió a pueblos leales como Llamellín, $40 \mathrm{~km}$ al este de Yacya, con tierras muy productivas32. Esta historia ofrece una descripción geológica del área ya que los ingredientes para las vasijas son obtenidos precisamente de Chinlla y Allpabamba. Del mismo modo sugiere las relaciones socioeconómicas del área: los pueblos cuyos territorios están llenos de shashal, tendrían menos tierras de cultivo, y por generaciones han debido ir a intercambiar el producto de su trabajo a lugares con buena agricultura, como Llamellín (fig. 1). La principal fuente de shashal de Chinlla está en la jallga, en Huaripampa (Huaychao) [09 $\left.06^{\prime} 16 \mathrm{~S} 077^{\circ} 23^{\prime} 43 \mathrm{O}, 3721 \mathrm{~m}\right]$, cerca de una hora cuesta arriba, según la ubicación de la casa del alfarero (cuadro 8, fig. 11). Los

32 Usamos la versión de T. Calero en Márquez (1965 [1946]: 150-1) y la de J. Laveriano (comunicación personal, 2005). 


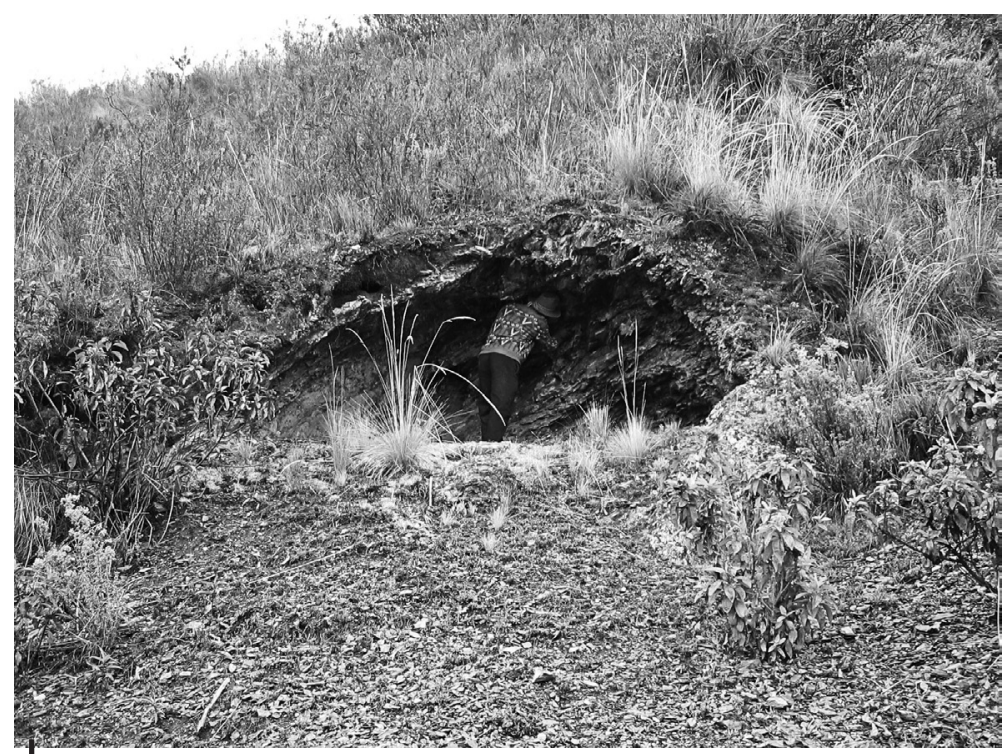

Figura 11 - Chinlla. Gerardo Cruz extrayendo shashal en una cantera de Huaychao, estación seca

Foto J. L. Pino

chinllinos usan arcilla de Allpabamba, y la recolección implica un día entero de trabajo. ¿Por qué los chinllinos deben caminar aproximadamente diez kilómetros al norte por este recurso? Según J. Laveriano: lluta allpa tsarantaacu shashalta [cualquier tierra no agarra al shashal]. Como en Conchucos meridional, en Chinlla, la piedra pizarra todavía es llamada shashal, sin embargo arcilla es ahora allpa, en lugar de racu. Acá allpa significa tierra en general y es específicamente aplicada a la materia prima para hacer ollas [manca allpa] (el nombre de la mina local de arcilla es Allpashpina, cuadro 8). Para las tejas se usa teja allpa, obtenida de canteras distintas. En Conchucos central, el racu solo sirve para hacer objetos como floreros, no para vasijas utilizadas en la cocina33.

Antes de la Reforma Agraria, las principales fuentes de shashal en Chinlla pertenecían a individuos, y los alfareros acostumbraban pagar por su uso. Hoy el shashal es libre para los chinllinos y la comunidad de Allpabamba es propietaria de su arcilla, que puede ser comprada/cambiada con shashal. Por ejemplo, C. Rivera obtiene arcilla en Allpabamba por la cantidad equivalente de shashal molido, como la mayoría de sus colegas (cuadro 9). Además de Allpabamba, Chinlla ha

33 En Chinlla, C. Rivera indicó que racu es la tierra húmeda de junto a las acequias; mitu es la mezcla de allpa, shashal y agua; allpa es tierra en general. R. Castellanos (Chacas-Uchusquillo) que aprendió alfarería en un taller urbano nos brindó una explicación complementaria: racu es cualquier barro, como el que se forma debajo del caño, y se puede moldear, pero solo sirve para hacer objetos no sometidos al fuego. Conclusión, en Conchucos central el racu está por doquier, el problema es identificar allpa. Esta distinción es clave cuando los arqueólogos hacen prospecciones para buscar potenciales canteras precoloniales. 


\section{Cuadro 9 - Piedra pizarra de los alfareros de Allpabamba}

Ch: Chinlla, U: Uchusquillo

\begin{tabular}{|c|c|c|}
\hline cantera de shalla/shashal & $\begin{array}{c}\text { destino: } \\
\text { Allpabamba }\end{array}$ & $\begin{array}{c}\text { Equivalencias } \\
\text { [arcilla / piedra pizarra molida] }\end{array}$ \\
\hline Chinlla & R. Arellano & $1 / 1$ \\
\hline Shagapampa $(U)$ & G. Carrión & $1 / 1-1.5$ \\
\hline Chinlla & W. Carrión & \\
\hline Chinlla & A. García & $1 / 2$ no molida \\
\hline Trancaragra (U) & J. García & $1 / 1$ \\
\hline Huaychao $(C h) /$ Shagapampa $(U)$ & N. Tarazona [C. Montero] & $1 / 1$ o $1 / 2$ no molida \\
\hline Huaychao $(C h) /$ Trancaragra $(U)$ & F. Vega [M.Vega] &
\end{tabular}

surtido lugares próximos con su shashal, todos dentro de la provincia de Asunción y al este de Yungay (Chucpín, Colpa, Huayá, Pampash, Sapchá, San Luis, Taulli, Tuma, Viscas, Yanama).

Cinco horas al norte de Chinlla está Allpabamba. Confirmando lo anotado por Tello (1938: XIV), alfareros de todo Conchucos central declararon que habían usado esta fuente (fig. 12, fig. 10). Antes de la Reforma Agraria, los allpabambinos pagaban por la arcilla en especies o trabajando para el hacendado. En las últimas décadas, para tener derecho a la arcilla los comuneros deben participar en los trabajos colectivos (e.g. limpiando las acequias). Varias personas dijeron que anualmente cada comunero puede recolectar cuatro sacos. Sin embargo, ya que la demanda de este material ha disminuido en la última década, parece que ahora solo se controla la extracción a manos de foráneos. Durante las lluvias la enorme cantera se inunda pero la arcilla puede obtenerse todo el año, ya que cada verano los allpabambinos la «cosechan» y la almacenan, como observó L. Vega [21].

En menor escala que Allpabamba, Uchusquillo es otra cantera extracomunal. Provee de shalla [el término local para shashal] a Allpabamba y lugares en el mismo distrito y en la provincia de Fitzcarrald (Canchabamba, Chacuascancha, Chincho, Illauro, Ocobamba, Ranraucro, Rosas Tayabamba, Yauya). Esto se vincula al menor tamaño de las fuentes de Uchusquillo en comparación con Allpabamba, y particularmente a que las fuentes de shalla están esparcidas por todo Conchucos, mientras la buena arcilla para ollas es rara34. La principal fuente de shalla en Uchusquillo es Trancaragra [08 $59^{\prime} 58 \mathrm{~S} 77^{\circ} 20^{\prime} 33 \mathrm{O}, 2887 \mathrm{~m}$ ] en el límite con el pueblo de Ishanca, junto a un arroyo (fig. 13). Una segunda fuente es Shagapampa (Tarapampa/Uchusquillo) [08 $59^{\prime} 45 \mathrm{~S} 77^{\circ} 20^{\prime} 42 \mathrm{O}, 2840 \mathrm{~m}$ ].

Los alfareros de Allpabamba obtienen su piedra pizarra de Uchusquillo (shalla) y Chinlla (shashal) principalmente, cambiándola por su arcilla local (cuadro 9). Aparte de la relación con Uchusquillo, a setenta minutos, las fuentes de materias

34 Información proporcionada por M. Martínez, alfarero de Conopa [16]. Según Raimondi (1873: 317) las canteras de carbón están frecuentemente asociadas con la piedra pizarra. Ver también la sección sobre carbón en la sección «reservas mineras» en Ancash, en minem.gob.pe. 


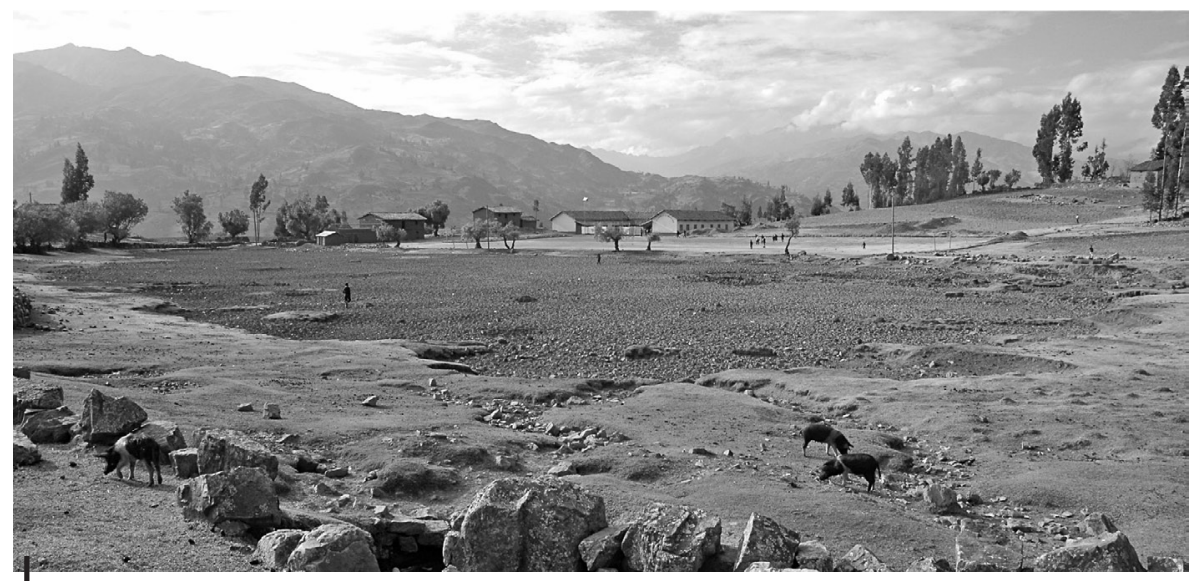

Figura 12 - Allpabamba. Cantera de arcilla (aprox. 120 x 60m)

Foto: G. Ramón

primas han creado un lazo especial entre pueblos relativamente distantes como Allpabamba y Chinlla. Los allpabambinos dicen que este vínculo ha perdurado por la buena calidad del shashal en Chinlla y asimismo porque a veces es difícil de obtener shalla en Uchusquillo.

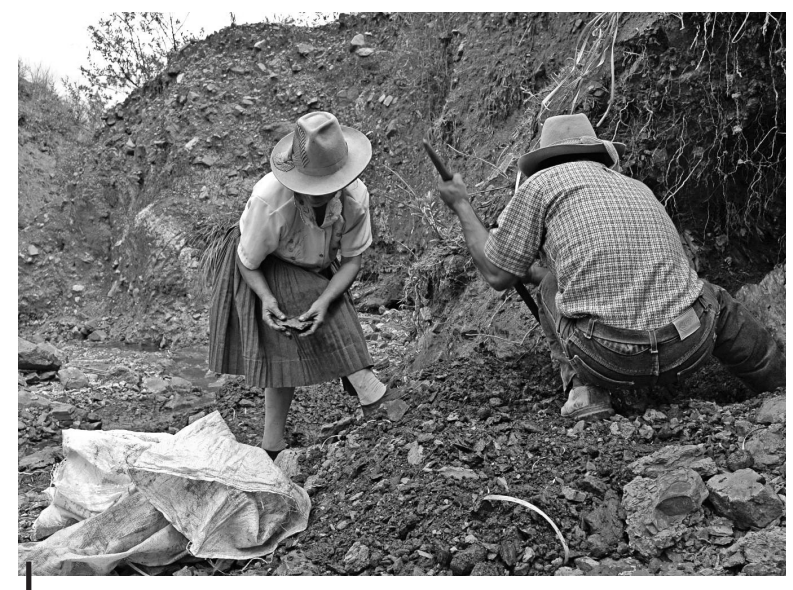

Figura 13 - Uchusquillo/Ishanca

D. y M. Ramírez extrayendo shalla en Trancaragra, a 20 minutos de su casa

Foto: G. Ramón

Como en Huari, en Conchucos central, se reconocen diferencias entre las principales categorías de materias primas. En Chinlla dos tipos de shashal han sido identificados: yana [negro], y puca [rojo] nominado a partir de la capa que lo cubre. El yanashashal es más suave y fácil de moler, pero más difícil de obtener. C. Rivera usa el pucashashal ya que la mina con el yanashashal (Huaripampa) colapsó a inicios de los años 1970, matando a dos alfareros. Una cantera alternativa y más cercana de yanashashal, Potrero, es usada por dos alfareros (cuadro 8). En Allpabamba y sus alrededores la gente reconoce varios tipos de piedra pizarra. G. Carrión [19] dijo que el yanashashal (suave) es para vasijas pequeñas y el blanco (más duro) es para vasijas grandes, ambos disponibles en Chinlla y Uchusquillo. En Tarapampa, B. Gaspar mencionó tres tipos de shalla: chukro [dura] para vasijas grandes como la ashuana o el urpu; medio chukro [media] para ollas [manca] y yiampu [suave] para vasijas chicas, todos en la misma cantera (Agoyracra). Complementariamente, otros alfareros observaron que la diferencia no está en la fuente sino en el procesamiento de las materias primas: para hacer vasijas grandes ellos solo muelen la shalla, para las pequeñas, además la ciernen (M. Morales [20], J. García [19]). 
En Conchucos central, la combinación normal de materias primas (una porción de arcilla por dos de shashal o shalla) es opuesta a la de Huari. En Chinlla, L. Vega observó que si solo usase shashal para hacer una vasija, se «caería», si solo allpa no resistiría el uso. El procesamiento de las materias primas es similar, con dos diferencias. Primero, en Chinlla el tuñay/maray se asemeja en tamaño (grande) y ubicación (fuera de la casa) al usado en Conchucos meridional, mientras que más al norte el instrumento se reduce y va dentro de las casas. Segundo, ambos materiales son molidos, pero en Allpabamba y Uchusquillo la piedra pizarra también es cernida35.

Como fue sugerido para Conchucos meridional, las actividades rituales parecen vincularse a la localización de las fuentes de materia prima: a medida que uno avanza hacia el norte de Conchucos (de Yacya a Uchusquillo) la altitud de las canteras de piedra pizarra disminuye, en más de mil metros, aproximándose a los centros poblados con alfareros. Para acceder a estas canteras en Yacya, la gente camina por más de cuatro horas hacia arriba, en Chinlla menos de una, y en Uchusquillo quince minutos. En comparación con Conchucos meridional, donde se venera a María Jirai, en Chinlla las evidencias rituales son poco frecuentes, pero J. Laveriano mencionó que antes de comenzar a extraer el shashal ellos acostumbraban chacchar coca e invocar al lugar para no ser aplastados: Ayilla jipiramusha niajyacha caya [Lo extraeré con cuidado]. En Uchusquillo ningún ritual fue mencionado.

\section{DISCUSIÓN: LA IMPRONTA TÉCNICA EN PERSPECTIVA REGIONAL}

Tal como fue indicado, reconocemos al menos tres estilos técnicos en Conchucos, basándonos en las herramientas y la secuencia de procedimientos utilizados para formar las vasijas. En el caso de Conchucos meridional se ha mostrado que características formales en el producto final, como la pequeña base plana, son diagnósticas. Cabe resaltar que al establecer estas diferencias solo estamos repitiendo algo ya conocido entre conchucanos. Siguiendo el testimonio de los alfareros, empecemos nuestra comparación desde Conchucos septentrional: en el pueblo de Conopa [16] le Ilaman chacasmanca [olla de Chacas, i.e. Chinlla] a las ollas con base plana en general. Esta distinción entre Conchucos septentrional y central se vincula con las herramientas (cf. [15-17] y [18-21]) y el proceso de manufactura: los alfareros del norte, es decir Conopa y las comunidades aledañas, tienen un paso diferente al hacer las ollas Ilamado tikray [voltear]. El tikray consiste en separar la vasija del molde de madera [muldi] y paletear su base que adquiere

35 Francisco Flores, alfarero de Pariahuanca (2010), nos contó que en 2007 invitado por una ONG viajó a Huari para entrenar alfareras. Para su sorpresa, las alfareras huarinas Ilamaban shashal al carbón de piedra, y él no podía hacer ollas con ese material mezclándolo con su arcilla de Pariahuanca. Sin embargo, luego de hacer sus pesquisas por los alrededores de Huari, Flores ubicó piedra pizarra. El shashal tiene diferente composición y diferente uso según la región. Considerado el indicado cambio de proporciones en la mezcla de materias primas, probablemente haya diferencias semejantes entre los shashales de Conchucos meridional y central. 
forma redondeada, perfecta para la tullpa, las tres piedras paradas usadas como armazón para cocinar en los caseríos de esa región (Castro-Pozo, 1924: 174) (fig. 14)36.

El mismo contraste técnico se observa entre Conchucos central y meridional, comenzando por las herramientas (comparar [18-21] y [2224]). El cambio es en los principales instrumentos diagnósticos. Primero, en lugar de la callhua, en Conchucos central se emplea una paleta de madera [paleto] y un yunque de cerámica [broquichu, cutana o tucllu, dependiendo del lugar; cf. Parker \& Chávez, 1976], y son usados de forma distinta que la callhua. Segundo, el plato de alfarero [tilla] en Conchucos central no tiene plataforma-base, por tanto rota más. Es menos plano y de diámetro mayor que en Huari (fig. 15)37. Las variaciones en los estilos técnicos pueden ser observadas en la morfometría de las vasijas, y

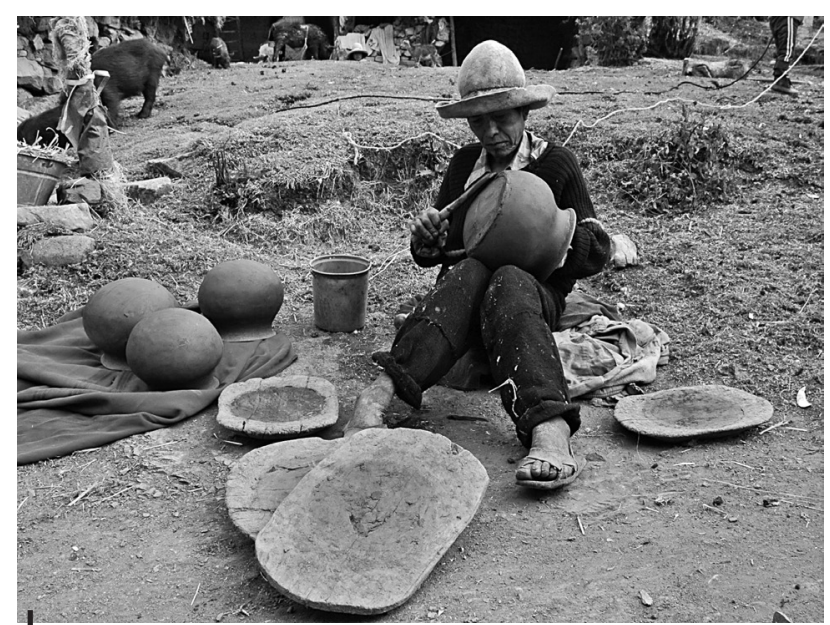

Figura 14 - Conopa. Justiniano Bolo paleteando la base, el paso tikray

Las ollas del costado ya han sido paleteadas. Los muldis son de madera (la secuencia completa en Ramón, 2008a: 413-415)

Foto: G. Ramón

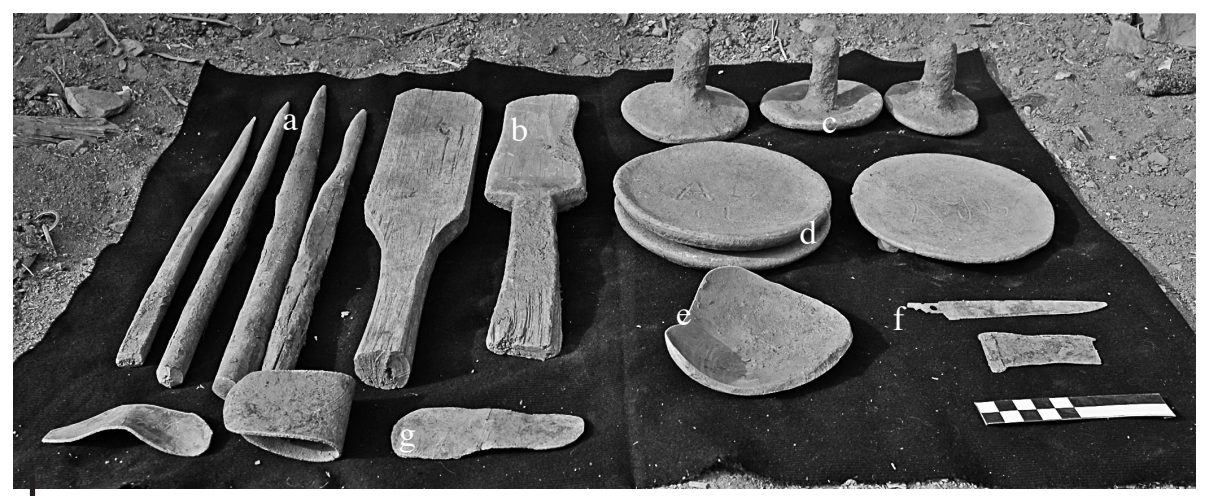

Figura 15 - Conjunto de herramientas Conchucos central

a. chogchi [baqueta], b. paleto [paleta], c. tucllu [golpeador de arcilla], d. tilla [plato], e. gachuina [mate], f. cuchillo de metal, g. shimiani [pieza de cuero]; A. García, Allpabamba, escala $10 \mathrm{~cm}$

Foto: G. Ramón

36 Las herramientas y la secuencia completa en Ramón (2008a: 399, 413-5).

37 En Chinlla, las dimensiones de la tilla pueden variar según los productos, e.g. las de C. Rivera van entre $9-22,3 \mathrm{~cm} \varnothing(n=11)$, y las de L. Vega, 13-19,5 cm Ø $(n=12)$. Comparar con la nota 30. 
especialmente en la base, del tipo de producto más común para nuestras áreas, la manca [olla] (fig. 16).
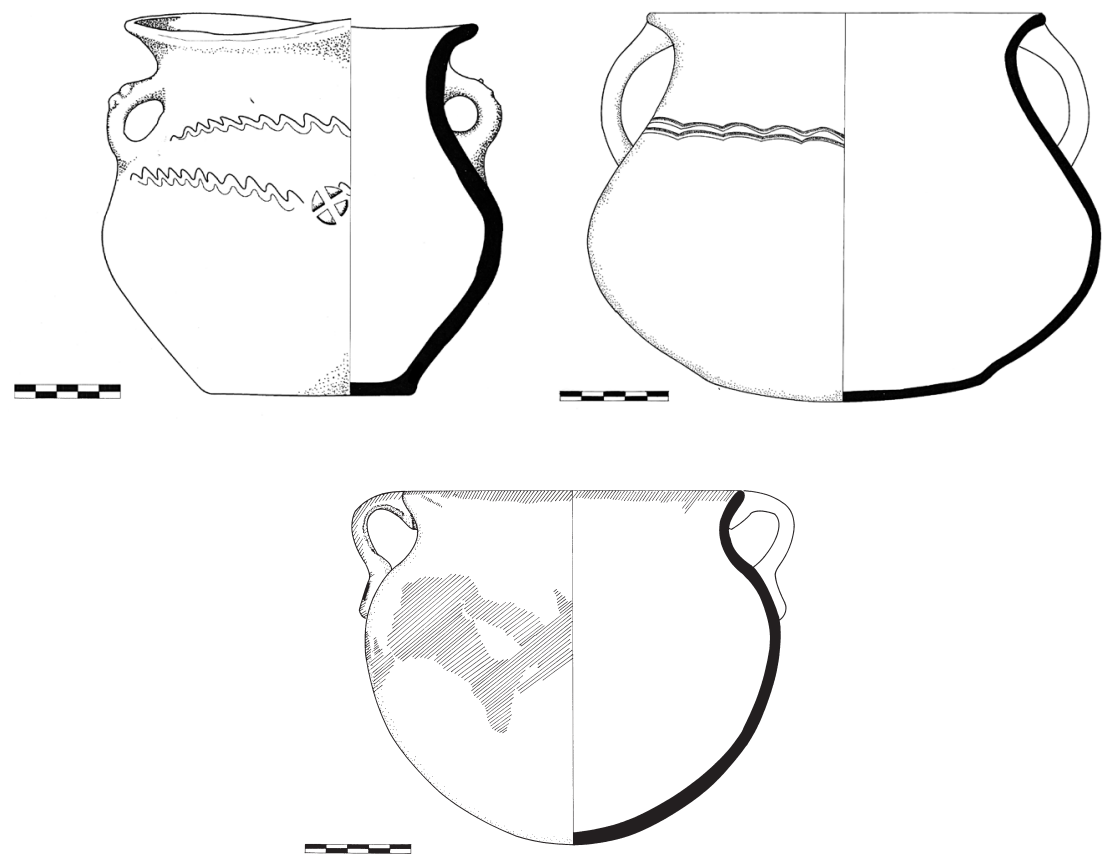

Figura 16 - Diferencias formales en las ollas de Conchucos

Nótese la base. Meridional (Yacya, F. Rojas), Central (Chinlla, O. Ríos), Septentrional (Conopa, B. Bermúdez), escala $5 \mathrm{~cm}$

Dibujos: D. Dávila y A. Neyra

Mientras los alfareros entrevistados en Conchucos septentrional no conocen a sus distantes colegas del extremo meridional, la interacción entre artesanos de áreas vecinas es común, especialmente por la indicada superposición de áreas de distribución. Por más de un siglo, los alfareros del área meridional y central han estado compartiendo ciertas zonas, como el mercado de Llamellín [H] o el pueblo de Huari [H] (fig. 1). Mostrando una gran familiaridad con las vasijas huarinas, el alfarero L. Vega [21] indicó que tienen paredes más gruesas y parecen trompos ya que usan una tilla menor. M. Gargate [21] criticó a sus colegas yacyinas señalando que ellas hacen vasijas rakta [grueso] que pesan mucho. J. Laveriano y su esposa [21] observaron que cuando una vasija es estrecha [churu] la llaman yacyamanca [olla de Yacya]. L. Vega [21] puede reconocer el producto final de otros lugares de Conchucos, como Uchusquillo, que vio durante sus viajes a la cantera de Allpabamba: esas vasijas tienen un pachan [barriga] más amplio, un shimi [boca] 
más estrecho, pero sin mayor variación en el putu [base]38. Esta última observación cuadra perfectamente con el registro material disponible: los alfareros de Chinlla y Uchusquillo, en Conchucos central, usan herramientas similares, y la forma de sus vasijas no es modificada luego de ser separadas del recipiente sobre el que se apoyan, como en Conopa.

Como se puede observar, las mencionadas variaciones técnicas también van acompañadas por una modificación en el vocabulario. Un caso ilustra estas relaciones. En Conchucos meridional arcilla es racu, y precisamente cuando los artesanos comienzan a usar otro estilo técnico, en Conchucos central, la arcilla es llamada allpa. A la vez, todos los alfareros de Conchucos central usan una fuente común, precisamente denominada Allpabamba, distinta a la usada por sus colegas del sur. El vocabulario cristaliza formas de interacción: que todos los usuarios de Allpabamba apliquen un mismo término para arcilla en una región donde sus vecinos inmediatos usan otro, sugiere contactos frecuentes relacionados con esta actividad, seguramente promovidos por la fuente geológica común. El hecho de compartir un estilo técnico puede considerarse una forma paralela de evidencia39.

A estas variaciones regionales algunas observaciones intracomunales deben ser agregadas. En cada comunidad visitada las personas pueden reconocer la «mano del alfarero», sin embargo para los consumidores de otras localidades todas ellas pertenecen a la misma unidad. Lo que deseo enfatizar aquí es que cada una de nuestras tres áreas tiene un estilo técnico particular e identificable por los propios conchucanos, quienes nunca aludieron a la decoración para hacer las distinciones entre poblados. Las discriminaciones sobre los productos finales hechas por los consumidores y los alfareros coinciden con nuestra distinción basada en los conjuntos de herramientas.

Finalmente, se podría argumentar que es posible elaborar vasijas de la misma forma usando diferentes herramientas alfareras. Ello es técnicamente posible, sin embargo, lo que empíricamente hemos observado en todos los Andes septentrionales peruanos (Ramón, 2008a; 2008b), y estamos mostrando en detalle para estos diez pueblos con alfareros repartidos en una región, es que la técnica solo cambia en el espacio cuando lo hacen los instrumentos. Habiendo documentado la diferencia formal entre las vasijas manufacturadas en Conchucos meridional, central y septentrional es necesario concluir en perspectiva.

${ }^{38}$ En el caso de la sierra de Piura los alfareros de Huarmaca [4] establecen la diferencia con las vasijas de sus colegas de Sondorillo [3], basándose en el mismo criterio que en Conchucos: la relación entre base y cuerpo (Ramón, 2008b: 498).

39 La divergencia en los nombres para la piedra pizarra brinda soporte complementario. Dentro de Conchucos central hay dos nombres distintos para este material, vinculados a su distribución. En Chinlla (como en la sección meridional) la piedra pizarra es shashal, en Uchusquillo shalla. En Allpabamba, donde la piedra pizarra proviene de ambas comunidades (Chinlla y Uchusquillo), se usan los dos nombres. En el norte deviene shilla (Conopa [16], y Llama [Tello, 1920]). 


\section{CONCLUSIONES: MODELANDO IDENTIDADES COLECTIVAS}

La etnografía comparada realizada en los pueblos con alfareros y sus canteras en una región andina confirma la necesidad de asumir el ciclo de vida de los objetos cerámicos como una red con, al menos, tres etapas marcadas por el movimiento. Primero, la conocida circulación de productos finales, la tradicionalmente denominada etapa de la distribución. Segundo, el frecuente, pero poco estudiado, desplazamiento de los lugares de manufactura, los alfareros golondrinos o productores itinerantes (Ramón, 2011). Tercero, la circulación de materias primas, aquí documentada para una zona con gran densidad de pueblos con alfareros ${ }^{40}$. Como hemos observado, esta etapa anterior a la manufactura puede ser particularmente dinámica. Por un lado, requiere el desplazamiento entre diversos puntos: canteras locales o regionales, y lugares de producción. Por otro, esta movilidad de materias primas resulta de las relaciones entre situación local y sistema regional. Pensemos, por ejemplo, en una serie de casos concretos registrados en Chinlla [21]. Dependiendo del tipo de vasija a elaborar, el plazo para concluirla, o, los contactos con comunidades vecinas, los alfareros chinllinos tienen varias opciones. Pueden emplear arcilla local, de canteras como Allpashpina, u obtenerla de una fuente más distante pero con buena reputación regional, caminando hasta Allpabamba, e incluso, pueden adquirir arcilla allpabambina con intermediarios. Aunque hay ciertas opciones recurrentes, el conjunto de alternativas mencionadas ha estado disponible para los alfareros chinllinos, y puede pensarse en situaciones comparables para sus colegas de otros pueblos vinculados a redes regionales de recursos. Es decir, todas estas posibilidades deben considerarse cuando nos enfrentamos al material andino precolonial. Finalmente, al tratar del movimiento de materias primas en Conchucos, debemos recordar que toda vasija para el fogón está siempre compuesta por dos ingredientes principales (arcilla y piedra pizarra o sus variedades) lo que obliga a pensar en dos redes de circulación, ya que tanto la localización como la distribución de estos ingredientes suele diferir (figs. 4, 10).

Mencionaré dos razones por las cuales es necesario tener en cuenta este conjunto de opciones empíricas documentadas en el panorama conchucano. Primera, para comprender el sistema de producción de objetos en los Andes, donde cada comunidad funciona dentro de un universo regional. En este contexto incluso productos supuestamente 'locales', como las vasijas domésticas, son elaborados con materia prima foránea, en ocasiones por alfareros de otras comunidades, de pueblos distantes. Al notable caso del pueblo de Chupán (Huánuco) — citado en nuestro epígrafe - cuyas vasijas llegaban desde Huari (Ancash), pueden agregarse las otras localidades o pueblos destino abastecidos por los pueblos con alfareros aquí presentados. En este sentido, la alfarería nos está permitiendo entender mejor las categorías de local y foráneo en los Andes. Segunda, la información conchucana sobre materias primas permitirá elaborar modelos para explicar el material

40 A las tres etapas indicadas se podría agregar la circulación de herramientas alfareras, documentada en África (Huysecom, 1992) pero todavía no en los Andes. 
precolonial desde una perspectiva comprehensiva. Esto justifica un esfuerzo de formalización regional, a fin de distinguir algunos elementos significativos, y sus posibles vínculos. En este trabajo hemos enfatizado en uno: la relación espacial entre la distribución geográfica de los estilos técnicos en una región y las esferas de interacción formadas alrededor de las canteras. Pudimos entonces abordar en Conchucos un punto clave de la historia rural andina y la arqueología ipor qué razones varias comunidades comparten un mismo estilo técnico? Sin descartar otros factores, esto puede comenzar a explicarse por las redes sociales generadas alrededor de las canteras. Para el caso conchucano vimos que el intercambio de materias primas alfareras suele implicar relaciones entre colegas, como en Conchucos central o septentrional, o personas cercanas al oficio, como en Conchucos meridional. Estos viajes requieren esfuerzo y recursos, haciendo más valiosa la experiencia sobre estos yacimientos. Las personas que usan estas canteras han compartido información sobre el uso de arcilla o piedra pizarra y sobre alfarería en general. La recurrente interacción en estos lugares permite concebirlos como fuentes de aprovisionamiento de recursos y de trasmisión de conocimientos, cuya materialización sería el estilo técnico común. En Conchucos meridional, el vínculo entre diversos pueblos puede ser considerado como una forma de reciprocidad entre localidades vecinas. En Conchucos central el intercambio se articula en un lugar central, generado por la disponibilidad geológica de las materias primas: desde que lo documentara Tello a inicios del siglo XX hasta hace una década, gente de toda esta región llegaba a la gran cantera de Allpabamba por arcilla. ¿Cómo emplear esta información en términos retrospectivos?

Ya que la relación entre canteras y estilos técnicos tiene implicancias directas para definir identidades colectivas a través de la cultura material, conviene hacer un par de observaciones, precisamente sobre Conchucos precolonial. Primera, como indicamos, tradicionalmente los arqueólogos se centraron en la etapa de la distribución de productos finales decorados para establecer sus mapas sobre grupos precoloniales. Los estudios etnográficos han permitido cuestionar esta premisa en dos sentidos. Por un lado mostraron que no había coincidencia entre los límites de un grupo étnico y la distribución de su cultura material, ya que en muchos casos los objetos localmente producidos (incluyendo a los denominados «marcadores étnicos») sobrepasaban rutinariamente las fronteras del grupo. Nuevamente, el ejemplo de Chupán abastecido con ollas desde Huari es ilustrativo. Si bien ignoramos cuándo comenzó esta práctica de vínculos distantes, es interesante que según un mapa étnico basado en fuentes coloniales (Rowe, 1974) el pueblo destino (Chupán) está dentro del territorio étnico Huamalí, y el lugar de manufactura dentro del territorio étnico Conchucos (Huari). Es decir, las ollas típicas de un grupo serían foráneas. Segunda, esta insuficiencia de la etapa de distribución de productos finales como criterio explicativo obliga a prestar atención a los otros pasos dinámicos del ciclo de vida alfarera, que permiten generar mapas complementarios, como la circulación de materias primas aquí discutida. En suma, como base para la definición de las identidades colectivas, debemos tomar en cuenta las diversas formas de articulación generadas entre los procesos que van desde la recolección de materias primas hasta la distribución de las vasijas. El panorama etnográfico conchucano presentado sugiere un punto de partida para explorar el material arqueológico, pero solo será extrapolable retrospectivamente en la medida 
que contemos con un marco analógico adecuado. Como hemos mostrado en detalle para la región actual de Conchucos, el compartir un estilo técnico se comprende por el uso de canteras similares, no inmediatamente por filiación étnica o política ${ }^{41}$.

En Conchucos, la ausencia de una base informativa sistematizada permite entender por qué los mapas étnicos sobre el área son problemáticos. Los dos mapas de Rowe (1946: mapa 3; 1974) basados en dos crónicas coloniales incluyen una significativa modificación para Ancash. En el primero el territorio de los conchucos corresponde al corregimiento y la subdelegación coloniales, con los pinco al sur (cf. Varallanos, 1959: mapas X, XI). En el mapa de 1974, los pinco han sido absorbidos por los conchucos. Las propuestas posteriores para identificar cartográficamente los grupos étnicos conchucanos son menos completas (ver Chocano, 2003; Ramón, 2005: 482)42. La identidad colectiva es un fenómeno multidimensional y en Arqueología contamos únicamente con objetos para definirla. Los mapas que podamos generar a partir de los diversos rasgos comunes reconocidos en el material precolonial son la base para toda respuesta. El resultado no será ni la suma de las partes, ni solamente sus puntos de intersección, ya que, como hemos visto para Conchucos, cada caso exige una explicación específica.

\section{Agradecimientos}

Dedico este trabajo a la familia de Maura Armas y Félix Crisóstomo (Uchusquillo). Desde Yacya hasta Llapo, desde Taricá hasta San Isidro la hospitalidad ancashina, y la paciencia de los alfareros nunca podrá ser suficientemente agradecida. El apéndice 1, es también una lista de quienes nos auxiliaron. Este artículo se basa en múltiples temporadas de campo, en las que aprendí de Giner Aranda (2003, 2004), Martha Bell (2004, 2005, 2010, 2011), Elvis Crisóstomo (2000, 2005), José Luis Pino (2001, 2005), Berenice Quintana (1999), Odolín Rodríguez (2003, 2011) y María Julia Tavera (2000). Elvis, Giner y Odolín dirigieron las entrevistas en quechua y se encargaron de esas transcripciones. Mis entrañables alumnos del Instituto Superior Don Bosco, Tomanga (Yungay) me ayudaron a entrevistar a los alfareros de Allpabamba y Chinlla (2003). El trabajo de campo para las largas temporadas de 2004 y 2005 se realizó bajo el generoso auspicio de la Sainsbury Research Unit, University of East Anglia, pacientemente asesorado por George Lau. George y Steve Wegner comentaron una versión previa y más extensa de este trabajo; Alexander Herrera y un revisor anónimo hicieron lo propio con la presente versión. La cartografía es de Martha Bell.

41 Recientemente Druc (2009) ha proyectado dos estilos técnicos actuales de Conchucos al pasado preinca asumiéndolos como estilos étnicos. Tres observaciones a esta hipótesis. Primera, según su mapa de grupos étnicos al tiempo de la conquista inca, el sur de Huari, inmediato a los centros alfareros del estilo técnico meridional está en territorio Pincos (:91), mientras tanto, en su mapa de parcialidades Huari, ese mismo territorio es Allauca Huari (:97). Así, según el mapa que usemos, Chavín de Huántar y Huántar cambian de grupo étnico. Segunda, ambos mapas —cruciales en su argumento- deberían estar claramente documentados con información colonial. En suma, me parece que antes de proyectar los dos estilos técnicos actuales al Horizonte Medio (:101) necesitamos mejor evidencia.

42 Una alternativa basada en documentos sería aplicar el método usado por Pärssinen (1992) en Huaylas. 


\section{Referencias citadas}

ARNOLD, D., 1985 - Ceramic Theory and Cultural Process, 286 pp.; Cambridge: Cambridge University Press.

ARNOLD, D., 1993 - Ecology and ceramic production in an Andean Community, 278 pp.; Cambridge: Cambridge University Press.

ARNOLD, D., 1998 - Ancient Andean Ceramic Technology: An Ethnoarchaeological Perspective. In: Andean Ceramics: Technology, Organization, and Approaches (I. Shimada, ed.): 353-367, vol. supplement 15; Philadelphia: Museum of Applied Science Center for Archaeology, University of Pennsylvania Museum of Archaeology and Anthropology.

ARNOLD, D., NEFF, H. \& BISHOP, R., 1991 - Compositional Analysis and "Sources" of Pottery: An Ethnoarcheological Approach. American Anthropologist, 93 (1):70-90.

CAMINO, L., 1983 - Tariká, un centro alfarero. Boletín de Lima, VI: 49-53.

CARMICHAEL, P., 1990 - Nasca Pottery Construction. Nawpa Pacha, 24: 31-48.

CARMICHAEL, P., 1998 - Nasca Ceramics: Production and Social Context. In: Andean Ceramics: Technology, Organization and Approaches, vol. Supplement 15 (I. Shimada, ed.): 213-231; Philadelphia: Museum of Applied Science Center for Archaeology, University of Pennsylvania Museum of Archaeology and Anthropology.

CASTRO POZO, H., 1924 - Nuestra Comunidad Indígena, 498 pp.; Lima: El Lucero.

CENSO GENERAL, 1878 - Censo general de la república del Perú. Formado en 1876. 9 vols. Lima: Imp. del Teatro.

CHAPDELAINE, C., KENNEDY, G. \& UCEDA, S., 1995 - Activación neutrónica en el estudio de la producción local de la cerámica ritual en el sitio moche, Perú. Bulletin de I'Institut Français d'Études Andines, 24 (2):183-212.

CHOCANO, M., 2003 - Las peripecias de un topónimo: Conchucos como realidad geográfica y como espacio histórico en la sierra norte peruana. Boletín del Instituto Riva-Agüero, 30: 173-196.

DIETLER, M. \& HERBICH, I., 1994 - Ceramics and ethnic identity: ethnoarchaoelogical observations on the distribution of pottery styles and the relationships between the social contexts of production and consumption. In: Terre cuite et societé: La céramique document technique, économique, culturel (F. Adudouze \& D. Binder, eds.): 459-72; Antibes: Editions APDCA.

DRUC, I., 1996 - De la etnografía hacia la arqueología: aporte de entrevistas con ceramistas de Ancash (Perú) para la caracterización de la cerámica prehispánica. Bulletin de I'Institut Francais d'Études Andines, 25 (1):17-41.

DRUC, I., 1998 - Ceramic production and distribution in the Chavín sphere of influence (North-Central Andes), 121 pp; Oxford: British Archaeological Reports.

DRUC, I., 2000 - ¿Shashal o no shashal? esa es la cuestión. Etnoarqueología cerámica en la zona de Huari, Ancash. Bulletin de I'Institut Français d'Études Andines, 30 (1): 157-173.

DRUC, I., 2005 - Producción cerámica y etnoarqueología en Conchucos Ancash-Perú, 110 pp.; Lima: Instituto Cultural Runa.

DRUC, I., 2009 - Tradiciones alfareras, identidad social y el concepto de etnias tardías en Conchucos, Ancash, Perú. Bulletin de I'Institut Français d'Études Andines, 38 (1): 87-106. 
ECHEANDÍA, J., 1983 - Alfarería tradicional en Taricá (Ancash), 51 pp.; Lima: Seminario de Historia Rural Andina.

FELTHAM, J., 2009 - La arqueología de Sisicaya. In: La revisita de Sisicaya (F. Salomon, J. Feltham \& S. Grosboll, eds.): 57-101; Lima: Pontificia Universidad Católica del Perú.

GOSSELAIN, O., 2002 - Poteries du Cameroun méridional. Styles techniques et rapports à I'identité, 256 pp.; París: CNRS.

GOSSELAIN, O. \& LIVINGSTONE SMITH, A., 2005 - The Source. Clay Selection and Processing Practices in Sub-Saharian Africa. In: Pottery Manufacturing Processes: Reconstruction and Interpretation (A. Livingstone Smith, D. Bosquet, \& R. Martineau, eds.): 33-47; Oxford: Archaeopress.

GOTTSMANN, S. \& TELLENBACH, M., 2002 - Exkurs: Drehscheibenkeramik?- Neues zur Keramik- technologie der Nascakultur. In: An die Machte der Natur. Mythen der altperuanischen Nasca-Indianer (A. Wieczorek \& M. Tellenbach, eds.): 54-63; Mainz am Rhein: Philipp von Zabern.

HUYSECOM, E., 1992 - Les percuteurs d'argile : des outils de potières africaines utilisés de la préhistoire à nos jours. Bulletin du Centre genevois d'anthropologie, 3: 71-98.

LATIN AMERICAN ANTIQUITY, 2006 - Latin American Amtiquity, 17 (1), marzo.

LÓPEZ-ALBÚJAR, E., 1937 - Nuevos Cuentos Andinos, 185 pp.; Santiago de Chile: Ediciones Ercilla.

LÓPEZ-ALBÚJAR, E., 1939 - Exégesis de la Justicia Penal Chupana. In: XXVI Congreso Internacional de Americanistas, vol. 2: 285-292; Lima.

MAKOWSKI, K., GHEZZI, I., GUERRERO, D., NEFF, H., JIMÉNEZ, M., ORÉ, G. \& ÁlVAREZ, R., 2008 - Pachacamac, Ychsma y los Caringas: estilos e identidades en el valle de Lurín Inca. In: Arqueología de la Costa Centro Sur Peruana (O. Pinero \& H. Tantaleán, eds.): 267-316; Lima: Auqui.

MÁRQUEZ, S., 1965 [1946] - Huari y Conchucos: monografía, 155 pp.; Lima: Imp. El Cóndor.

MIDDENDORF, E., 1974 [1886] - Perú: observaciones y estudios del país y sus habitantes durante una permanencia de 25 años. Vol. III: La sierra (3 vols.); Lima: UNMSM.

MOHR, K., 1984-1985 - Traditional pottery of Raqch'i, Cuzco, Perú: a preliminary study of its production, distribution and consumption. Nawpa Pacha, 22-23: 161-210.

MORALES, D., 1981- Los alfareros de Huánuco, 66 pp.; Lima: SHRA.

O'NEALE, L., 1976 - Notes on pottery making in highland Peru. Nawpa Pacha, 14: 41-59.

PARKER, G., 1976 - Gramática Quechua: Ancash-Huailas, 187 pp.; Lima: Ministerio de Educación, IEP.

PARKER, G. \& CHÁVEZ, A., 1976 - Diccionario Quechua: Ancash-Huailas, 311 pp.; Lima: Ministerio de Educación.

PÄRSSINEN, M., 1992 - Tawantinsuyu. The Inca State and its Political Organization, 462 pp.; Helsinki: Societas Historica Finlandiae.

PETREQUIN, P. \& PETREQUIN, A.-M., 1999 - La poterie en Nouvelle-Guinée : savoir faire et transmission des techniques. Journal de la Societé des Océanistes, 108: 71-101.

PROULX, D., 1968 - Local differences and time differences in Nasca pottery, 180 pp.; Berkeley: University of California Press.

RAIMONDI, A., 1873 - El departamento de Ancachs y sus riquezas minerales, 640 pp.; Lima: El Nacional.

RAIMONDI, A., 1929 - El Perú. Itinerarios de viajes. Lima: Torres Aguirre. 3 vols. 
RAMÓN, G., 1999 - Producción alfarera en Santo Domingo de los Olleros (HuarochiríLima). Bulletin de I'Institut Français d'Études Andines, 28 (2): 215-248.

RAMÓN, G., 2005 - Reseña de Druc (2005). Bulletin de I'Institut Français d'Études Andines, 34 (3): 480-485.

RAMÓN, G., 2008a - Potters of the Northern Peruvian Andes: a palimpsest of technical styles in motion, 437 pp.; Universidad de East Anglia: tesis de Doctorado.

RAMÓN, G., 2008b - Producción alfarera en Piura (Perú): estilos técnicos y diacronía. Bulletin de I'Institut Français d'Études Andines, 37 (3): 477-509.

RAMÓN, G., 2011 - The swallow potters: seasonally migratory styles in the Andes. In: Archaeological ceramics, a review of current research (S. Scarcella, ed.): 160-175; Oxford: British Archaeological Reports.

REICHEL-DOLMATOFF, G., 1945 - La manufactura de cerámica entre los Chami. Boletín de Arqueología, 1: 425-430.

RENFREW, C., 1975 - Trade as Action at a Distance: Questions of Integration and Communication. In: Ancient Civilization and Trade (J. Sabloff \& C. LambergKarlovsky, eds.): 3-59; Alburquerque: University of Nuew Mexico Press.

ROARK, R., 1965 - From Monumental to Proliferous. Nawpa Pacha, 3: 1-92.

ROHFRITSCH, A., 2010 - Contribución arqueométrica al estudio de las técnicas y de la organización de la producción de cerámica ritual en la sociedad Mochica (150-850 d.C., costa norte del Perú). Bulletin de I'Institut Français d'Études Andines, 39 (2): 389-412.

ROWE, J., 1944 - Introduction to the archaeology of Cuzco, 69 pp.; Cambridge: Harvard University. Papers of the Peabody Museum of American Archaeology and Ethnology 27.

ROWE, J., 1946 - Inca culture at the time of the Spanish Conquest. In: Handbook of South American Indians, vol. 2 (J. Steward, ed.): 183-330; Washington: Smithsonian Institution.

ROWE, J., 1956 - Archaeological explorations in southern Peru, 1954-1955. Preliminary Report of the Fourth University of California Archaeological Expedition to Peru. American Antiquity, 22 (2): 135-151.

ROWE, J., 1960 - Nuevos datos relativos a la cronología del estilo Nasca. In: Antiguo Perú: espacio y tiempo: 29-45; Lima: Mejía Baca.

ROWE, J., 1974 - Indian Tribes of South America. Tribal Distributional Map. In: Native South Americans. Ethnology of the Least Known Continent (P. Lyon, ed.); Boston: Little, Brown and Company.

SILVERMAN, H. \& PROULX, D., 2002 - The Nasca, 339 pp.; London: Blackwell.

STEIN, W., 1961 - Hualcán: life in the highlands of Peru, 383 pp.; Ithaca: Cornell University Press.

TELLO, J., 1920 - Documento «Sra. Ibulich» [manufactura alfarera en Llama, Ancash] [tipografiado], Grupo Muchik, Paquete 1, Folder 2, p. 51, Tecnología Inca, Archivo Tello, Museo de Arqueología y Antropología, Universidad Nacional Mayor de San Marcos, Lima.

TELLO, J., 1938 - Arte Antiguo Peruano. Álbum fotográfico de las principales especies arqueológicas de cerámica Muchik existentes en los museos de Lima. Primera parte: tecnología y morfología. Inca 2: VII-LXII, 1-280.

TOSI, J., 1960 - Zonas de vida natural en el Perú: memoria explicativa sobre el mapa ecológico del Perú, 271 pp.; Lima: Instituto Interamericano de Ciencias Agrícolas de la OEA. 
TSCHAUNER, H., 2006 - Chimu craft specialization and political economy: a view from the provinces. In: Andean Archaeology III: North and South, vol. 3 (W. Isbell \& H. Silverman, eds.): 171-196; New York: Springer.

UHLE, M., 1902 - Types of culture in Peru. American Anthropologist, 4 (4): 753-759.

URBANO, J. \& MACERA, P., 1992 - Santero y Caminante. Santoruraj-Ñampurej, 194 pp.; Lima: Apoyo.

VARALLANOS, J., 1959 - Historia de Huánuco: introducción para el estudio de la vida social de una región del Perú. Desde la era prehistórica a nuestros días, 672 pp. Buenos Aires: López.

VAUGHN, K., 2009 - The Ancient Andean Village. Marcaya in Prehispanic Nasca, 209 pp.; Tucson: University of Arizona Press.

VAUGHN, K. \& NEFF, H., 2000 - Moving beyond iconography: neutron activation analysis of ceramics from Marcaya, Peru, an early Nasca domestic site. Journal of Field Archaeology, 27 (1): 75-90.

VAUGHN, K. \& NEFF, H., 2004 - Tracing the clay source of Nasca polychrome pottery: results from a preliminary raw material survey. Journal of Archaeological Science, 31 (11): 1577-1586.

VAUGHN, K., CONLEE, C., NEFF, H. \& SCHREIBER, K., 2006 - Ceramic production in ancient Nasca: provenance analysis of pottery from the Early Nasca and Tiza cultures through INAA. Journal of archaeological Science, 33 (5): 681-689. 


\title{
Apéndice 1 - Alfareros e informantes de Conchucos meridional y central
}

\author{
Abreviaturas: e: esposo/a, $h$ : hermana/o, hi: hija/o, $m$ : madre, $p$ : padre, $s$ : \\ sobrino, $t$ : tía, \\ t: fallecido. Nuestros totales en el texto, se refieren a alfareros activos. El caserío \\ va entre paréntesis.
}

\section{Acopalca}

1. Donata Agreda [hi de 9], 2. Paulina Castilla, 3. Leonarda Castillo [Anselmo Vidal, e], 4. Margarita Chavez, 5. Labiana Jara Soto [Darío Ortiz, e], 6. Fidela Tello, 7. Margarita Yauri C., 8. Maura Yauri [Marcelino Rodríguez, e; Santos Yauri, p] , 9. Ampelia Zamudio

\section{Mallas}

1. Alejandra Hidalgo [Silvano Hidalgo, e] , 2. Cirila Mendoza, 3. Donatella Rivera, 4. Oswalda Trejo, 5. E. Salas

\section{Poyoyoc}

1. Benedicta Flores, 2. Lucila Flores, 3.Alicia Jerónimo, 4. Antu Muñoz, 5. Bonifacia Robles, 6. Indelsa Soto [†], 7. Carmina Sulhuada, 8. Tomasa Zorilla

\section{Yacya}

1. Gertrudis Adán, 2. Florentina Cadillo, 3. Sabina Carhuapoma [t de 20], 4. Apolonia Gómez, 5. Julia Inca [?], 6. Gregoria Gregorio, 7. Prudencia Gregorio Santiago [t de 14], 8. Maura Inca Rojas [s de 10], 9. Jacinto Janampa Pascual (Alcalde), 10. Rufina Mori, 11. Aniceta Ocaña Janampa de Inga Rojas, 12. Lucia Ocaña, 13. Prudencia Ocaña, 14. Rosa Palacios, 5. Felicita Rojas Gregorio, 16. Gertrudis Rojas, 17. Lila Rojas S., 18. Priscila Rojas C. [†], 19. Rosalinda Rojas, 20. Gregoria Santiago [he de 21 ], 21. Julia Santiago C. 22. Vitoria Santiago [†], 23. Rudi Tolentino

\section{Chinlla}

1. Bautista Cruz Lanchi [†] (Huaycho), 2. Gerardo Cruz Sotelo (Huaycho), 3. Martín Amancio Falcón (IchiqChinlla), 4. Martín Gargate , 5. Jesús Laveriano, 6. Rufino Minaya (Huayush), 7. Maxi Rios (San Bartolomé), 8. Oswaldo Ríos (Ichiq Chinlla), 9. Clímaco Rivera (Ichiq Chinlla; nacido cerca a Huari), 10. Ciro Sifuentes (nacido en Huari), 11. Claudio Tafur, 12. Concepción Vega (Huayush), 13. Eugenio Vega (Ichiq Chinlla), 14. Lucio Vega (San Bartolomé) [Teodosia Vega, e] 


\section{Uchusquillo}

1. Alejandro Andahua [hi de 2], 2. Marcelo Andahua [t], 3. Rufino Andahua Mendoza [he de 2], 4. Alfonso Ayala [t], 5. Emiliano Ayala, 6. Julio Ayala [hi de 7], 7. Martín Ayala [t], 8. Nicanor Blas [t], 9. David Damaso [†], 10. Edilberto Julca [†], 11. Alejo Luna, 12. Fortunato Luna, 13. Genaro Luna, 14. Julio Luna, 15. Leoncio Llanca Luna, 16. Idelfonso Mendoza, 17. Vicente Mendoza, 18. Laurino Montesinos Mendoza, 19. Federico Morales [†], 20. Marcelino Morales 21. Rumaldo Morales, 22. Gregorio Moreno, 23. Marciano Moreno (Ishanca), 24. Emilio Moreno Cruz, 25. Justo Perez (en Huaral), 26. Máximo Ramírez, 27. Sebastián Santiago 